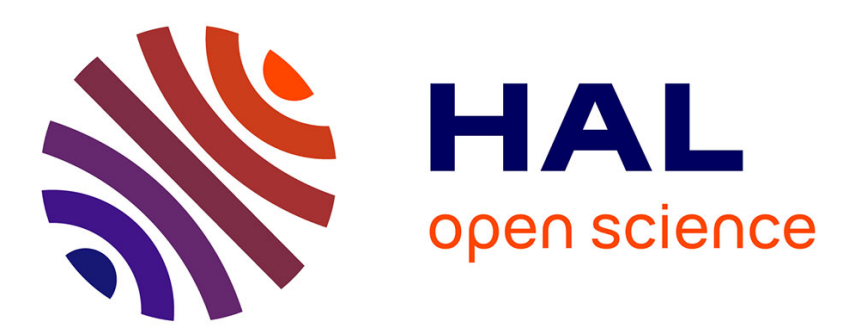

\title{
Proton exchange membrane fuel cell degradation prediction based on Adaptive Neuro-Fuzzy Inference Systems .
}

R.E. Silva, Rafael Gouriveau, Samir Jemei, Daniel Hissel, Loïc Boulon, Kodjo Agbossou, Nadia Yousfi Steiner

\section{To cite this version:}

R.E. Silva, Rafael Gouriveau, Samir Jemei, Daniel Hissel, Loïc Boulon, et al.. Proton exchange membrane fuel cell degradation prediction based on Adaptive Neuro-Fuzzy Inference Systems .. International Journal of Hydrogen Energy, 2014, 39, pp.11128-11144. 10.1016/j.ijhydene.2014.05.005 . hal-01050920

\section{HAL Id: hal-01050920 \\ https://hal.science/hal-01050920}

Submitted on 25 Jul 2014

HAL is a multi-disciplinary open access archive for the deposit and dissemination of scientific research documents, whether they are published or not. The documents may come from teaching and research institutions in France or abroad, or from public or private research centers.
L'archive ouverte pluridisciplinaire HAL, est destinée au dépôt et à la diffusion de documents scientifiques de niveau recherche, publiés ou non, émanant des établissements d'enseignement et de recherche français ou étrangers, des laboratoires publics ou privés. 


\title{
Proton Exchange Membrane Fuel Cell degradation prediction based on Adaptive Neuro Fuzzy Inference Systems
}

\author{
R.E. Silva ${ }^{\mathrm{a}, \mathrm{b}, \mathrm{c},{ }^{*},}$, R. Gouriveau ${ }^{\mathrm{a}, \mathrm{b}, \mathrm{d}}$, S. Jemeí ${ }^{\mathrm{a}, \mathrm{b}}$, D. Hissel ${ }^{\mathrm{a}, \mathrm{b}}$, L. Boulon ${ }^{\mathrm{c}}$, K. Agbossou ${ }^{\mathrm{c}}$ and N. Yousfi Steiner ${ }^{\mathrm{e}}$ \\ a FEMTO-ST Institute UMR CNRS 6174, Université de Franche-Comté, Techn'Hom 90010 Belfort Cedex, \\ France \\ ${ }^{\mathrm{b}}$ FCLAB FR CNRS 3539, Techn'Hom 90010 Belfort Cedex, France \\ ' IRH, Institut de Recherche sur l'Hydrogène, Université du Québec à Trois-Rivières, Trois-Rivières, Canada \\ d ENSMM, National Engineering Institute in Mechanics and Microtechnologies, 26 Rue de l'Épitaphe 25000 \\ Besançon, France \\ ${ }^{\mathrm{e}}$ EIFER, European Institute for Energy Research, Emmy-Noether Str. 11, 76131 Karlsruhe, Germany
}

\section{ARTICLE INFO}

Article history:

Received December 2013; Received in revised form XX XX XXXX; Accepted XX XX XXXX; Available online XX XX XXXX

\section{Keywords:}

Proton Exchange Membrane fuel cell degradation, Prognostic and Health Management, Time-series prediction, Adaptive Neuro-Fuzzy Inference System.

\section{[*] Corresponding author, silvasan@uqtr.ca}

\begin{abstract}
This paper studies the prediction of the output voltage reduction caused by degradation during nominal operating condition of a PEM fuel cell stack. It proposes a methodology based on Adaptive NeuroFuzzy Inference Systems (ANFIS) which use as input the measures of the fuel cell output voltage during operation. The paper presents the architecture of the ANFIS and studies the selection of its parameters. As the output voltage cannot be represented as a periodical signal, the paper proposes to predict its temporal variation which is then used to construct the prediction of the output voltage. The paper also proposes to split this signal in two components: normal operation and external perturbations. The second component cannot be predicted and then it is not used to train the ANFIS. The performance of the prediction is evaluated on the output voltage of two fuel cells during a long term operation (1000 hours). Validation results suggest that the proposed technique is well adapted to predict degradation in fuel cell systems.
\end{abstract}

\section{Introduction}

Fuel Cell Systems (FCS) and in particular Proton Exchange Membrane Fuel Cells (PEMFC) appears to be an alternative to reduce the dependence on fossil energy, one of the economic and environmental challenges of modern society. The advantages of this technology include high efficiency, low emissions, fast system start-up ability, and high power density. However, they have several drawbacks such as complex water and heat management, intolerance to impurities in incoming gases and slow kinetics of oxygen reduction reaction. FCS are not yet ready to be considered for large scale industrial development, indeed further efforts must be undertaken to optimize this technology, particularly by increasing its reliability and lifespan [1-4]. PEMFC durability is affected by factors such as stack design and assembly, materials degradation, operating conditions, impurities and contaminants [5-8]. The operation of the fuel cell causes degradation which always involves a reduction in the output voltage and then a loss of performance because of the reduction in the output power. Moreover, each fuel cell has a unique degradation profile based on its history and operating conditions. Degradation is an unavoidable condition; nevertheless it can be minimized and even mitigated with effective prognostics and diagnostics tools.

Prognostics is the process of predicting the future condition of a system based upon current and previous system states. Prognostics systems aim to predict the Remaining Useful Life (RUL) of the system and to determine when maintenance should be performed for avoiding equipment breakdown 
[9-15]. Several recent studies focus on the implementation of Prognostic and Health Management (PHM) methods to guarantee a safe longer term operation and to increase reliability and availability while reducing maintenance and operating cost. PHM encompasses the following core areas: avionics [16-18] electronic systems [19-22], power and energy systems [23-25], structural degradation [26-29], healthcare and medical technology [30, 31] and so forth. Prognostic of FCS is a relatively new field of research where only few works have been published. Among these works, Wang et al. [32] proposes to use Kalman Filters, in [33] the authors propose a Solid Oxide Fuel Cell model based on Neural Networks, and Jouin et al. [34] summarizes the current state of the art on prognostic and health management for PEM fuel cell systems.

Prognostics approaches are classified into three categories: model-based also known as Physics of Failure (PoF), data-driven, and fusion approach. Model-based methods assume that an accurate mathematical model can be constructed from physical understanding of the system [35-38]. Datadriven approaches use historical data to estimate degradation, their main interest is their ability to represent complex and non-linear relationships among data [39-42]. The fusion approach combines the advantages of data-driven and model-based methods [13, 43-45].

Fuel cell systems are complex multi physics (electric, fluidic, electrochemistry, thermal and mechanical phenomena) and multi scale (time and space) systems. The modeling of their degradation is a difficult task, as consequence of its nonlinear nature, the non-reversibility of their reactions and the interactions between their multiple subsystems. PHM tools must be implemented in a FCS to anticipate and avoid failures, to estimate mid-term and/or long-term State of Health $(\mathrm{SoH})$ and to decide upon mitigation and control strategies. This is the reason why data-driven are more adapted than model-based approaches for performing prognostics of fuel cell systems.

Data driven approaches for prognostic can be divided into two categories: statistical techniques and artificial intelligence techniques (such as neural networks, fuzzy systems, neuro-fuzzy systems). Among these techniques, Adaptive Neuro-Fuzzy Inference Systems (ANFIS) are considered because they do not require complex mathematical models, they are fast and adaptive and the developed prediction tool can be implemented on-line, which is essential for PHM of fuel cell systems. Their principal drawback is that the performance of the predictions is highly depending in quantity and quality of data [46-49]. Approaches based on the use of experimental data to construct neuro-fuzzy inference systems have been used in a variety of applications such as medical [50-52], motors [53-55] and fuel cell diagnosis [56]. Moreover, ANFIS has been used to performance (current-voltage curve) prediction of a PEMFC [57].

The first contribution of this paper consists in defining the architecture of the ANFIS prediction system that is defining the inputs and outputs of the system as well as to determine the parameters to train. This is done by considering not only the accuracy of the system but also its ability to be implemented into real-time. The second main contribution of this paper consists in proposing a method to reduce the error in the predictions caused by external perturbations in the output voltage (such as transients when the fuel cell is started). Therefore, the paper proposes to split the signal in two components: the voltage due to normal operation and a second caused by external perturbations.

This paper is organized as follows: Section 2 provides the research context about fuel cell systems, prognostics and health management, and ANFIS. Section 3 introduces the ANFIS-based prediction methodology and the evaluation of its performance. Section 4 illustrates the implementation of the methodology by predicting the Mackey-Glass temporal series, the prediction of this time-series is a benchmark problem widely used in the literature as reference to evaluate the performance of prediction tools [58-60]. The methodology to predict the output voltage in a fuel cell is presented in Section 5. The final section presents the conclusion and outlooks.

\section{Research context}

One of the challenges to develop fuel cell systems in an industrial scale is to optimize them, particularly by increasing their reliability and lifespan. FCS degradation has to be studied to quantify their Remaining Useful Life (RUL) and therefore reduce the risk of failure. As the stack voltage is the simplest indicator of the SoH and performance of the FCS, this paper proposes a methodology to predict the voltage decrease due to the degradation under nominal operating condition. Operation of the PEM fuel cell system under nominal conditions is referred to the parameters that have to be set by 
the user to keep the system in its optimum performance. Taking into account the high complexity of fuel cell systems, the methodology is based on ANFIS. In general, ANFIS enables diagnostics/prognostics because of its abilities to learn, to model nonlinear functions without explicit knowledge of its physical behavior [61-63]. Thus, it can be used to lifespan estimation and then integrated in the maintenance activities to ensure the reliability of FCS.

\subsection{Fuel cell prognostics and health management}

Prognostics and health management of fuel cell systems is performed by following the next four stages: data acquisition, data preprocessing, diagnostic and prognostic, and decision making, as illustrated in Fig. 1. This paper focuses on the first three stages of the PHM methodology explained below.

Data acquisition: related to collecting and storing information about the state of operation of the FCS. These information is collected using sensors to measure as non-intrusive as possible, physical quantities such as cooling water, and inlet and outlet Air $/ \mathrm{H}_{2}$ temperatures (thermal), stack voltage, stack current (electrical), Air/ $\mathrm{H}_{2}$ inlet/outlet pressures, vibration (mechanical), and gas humidity level, presence of contaminants (chemical).

Data preprocessing: allows filtering signal noise by extracting and selecting features (model parameters) from raw data collected by the sensors to characterize the operation of the FCS. Classical data pre-processing techniques for PEMFC include: electrochemical impedance spectroscopy (dynamic characterization) and polarization curve measurements (static characterization).

The raw data is processed to be used in a prognostic model. This can include filtering or splitting of the signal as explained in Section 5.4.

Diagnostic/Prognostic model: firstly, using data from the former stages, the operating mode of the FCS is compared with a reference healthy operation mode. Deviations from the normal operation allow identifying and isolating causes and mechanisms of failure. The module generates alerts based on defined operational limits $[10,15]$. Secondly, the prediction of the future condition of the FCS system and its RUL based upon current and previous system states $[10,11,15]$. This module takes into account trends in the health history, operating conditions, power demands, and the maintenance history [15]. In this paper, the prediction of the degradation in the FCS is based on the output voltage because it is the simplest indicator, a non-intrusive and low expensive measure to implement. It should be noticed that this enables estimating the degradation but not identifying the failure or degradation modes.

Decision Making: allows scheduling maintenance/actions to be taken before failures occurs. 


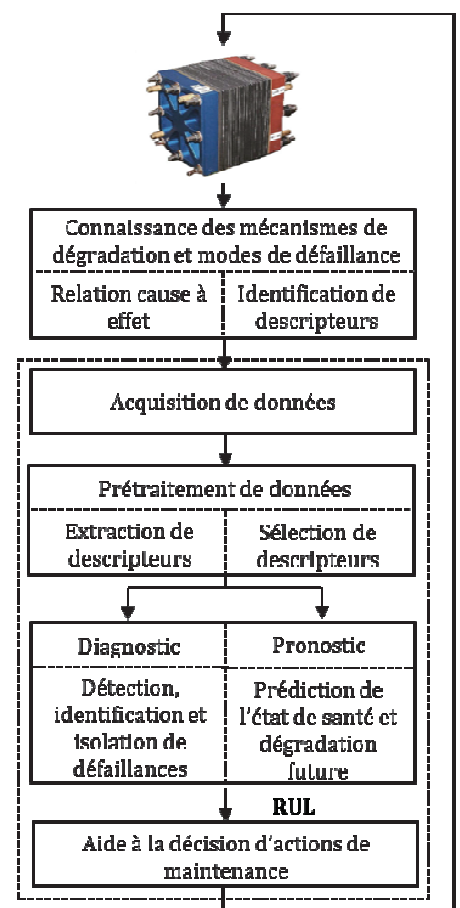

Fig. 1 - PHM in PEM Fuel Cells.

\subsection{Adaptive Neuro-Fuzzy Inference Systems (ANFIS)}

Fuzzy Logic (FL) is a computational technique which uses linguistic labels to represent numbers for computing and reasoning. Fuzzy systems are constructed from a collection of fuzzy "if-then" rules and Membership Functions (MFs) which define the relationship between input and output variables. Fuzzy rules and membership functions are defined either by using human knowledge or by using data from the system [64]. Considering the lack of expertise in fuel cell lifespan estimation and the high complexity of FCS, the design of a fuzzy system to predict loss of performance based on human experience is prohibitive. Therefore, the design of such system has to be made using experimental data.

ANFIS is a class of adaptive networks introduced by Jang et al., [65] and exploited recently to support forecasting tasks. It can be seen as a feed-forward neural network structure where each layer is a neuro-fuzzy system component. ANFIS methodology is in essence a fuzzy logic system, where the system parameters are optimized via neural network training. This adaptive technique uses the learning ability of an ANN to define the rules and membership functions of the fuzzy logic system.

Fig. 2 describes the architecture of ANFIS and briefly explains the learning and inferring process. If the input layer is composed of four crisp input variables $\left\{x_{1} x_{2} x_{3} x_{4}\right\}$, and two membership functions are assigned to each input variable (like in Fig. 2), then 16 rules are formulated for the inference operation $\left(2^{4}\right)$. These rules are represented in general form in the following manner:

$R_{j}$ : If $\left(x_{1}\right.$ is $\left.A_{1}^{j}\right)$ and $\left(x_{2}\right.$ is $\left.A_{2}^{j}\right)$ and $\left(x_{3}\right.$ is $\left.A_{3}^{j}\right)$ and $\left(x_{4}\right.$ is $\left.A_{4}^{j}\right)$

then $y^{j}=c_{1}^{j} x_{1}+c_{2}^{j} x_{2}+c_{3}^{j} x_{3}+c_{4}^{j} x_{4}+c_{5}^{j}$

where $j=1, \ldots, 16$ is the rule number, $y^{j}$ is the output result according to the $j^{\text {th }}$ fuzzy rule, $A_{i}^{j}$ is the fuzzy set associated with the $i^{\text {th }}$ input variable in the $j^{\text {th }}$ fuzzy rule, and $c_{k}^{j}$ is the consequence or the parameter which is determined during the training process; here, $i=1,2, \ldots, 4$ and $k=1,2, \ldots, 5$. 


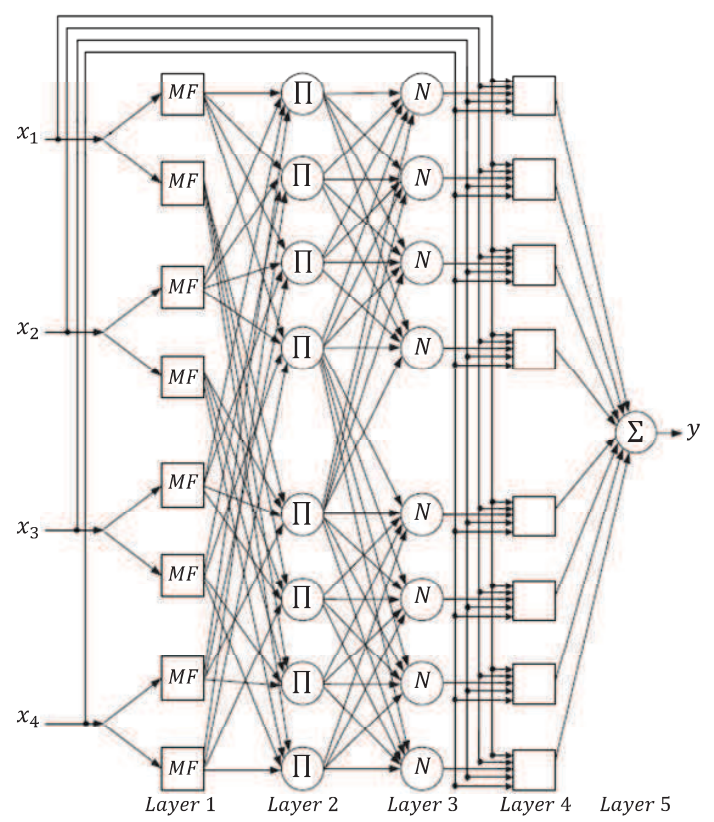

Fig. 2 - ANFIS architecture.

The ANFIS network is composed of five layers as shown in Fig. 2. A node within the same layer performs functions of the same type: note that a circle indicates a fixed node whereas a square indicates an adaptive node (the parameters are changed during adaptation or training).

In Table 1 is presented layer by layer a brief description of the ANFIS architecture, $x_{i}^{(k)}$ defines the $i^{\text {th }}$ node input in the $k^{\text {th }}$ layer, and $y_{i}^{(k)}$ denotes the $i^{\text {th }}$ node output in the $k^{\text {th }}$ layer.

\begin{tabular}{|c|c|c|c|c|}
\hline Layer $\mathrm{N}^{\circ}$ & Brief description & Equations & & Eq. $\mathrm{N}^{\circ}$ \\
\hline 1 & $\begin{array}{l}\text { Generates a membership } \\
\text { grade of a linguistic label } \\
\text { where } A_{i}^{j} \text { is the linguistic la } \\
\text { fuzzy rule, and }\left(a_{i}, b_{i}, c_{i}\right) \\
\text { as the premise parameters }\end{array}$ & $\begin{array}{l}\qquad y_{i}^{(1)}=\mu_{A_{i}^{j}}\left(x_{i}^{(1)}\right)=\frac{1}{1+\left|\frac{x_{i}^{(1)}-c_{i}}{a_{i}}\right|^{2 b_{i^{\prime}}}} \\
\text { bel (small, large, etc.) associated to the } i^{t h} \text { input varia } \\
\text { s the parameter set that changes the shapes of the MF a }\end{array}$ & $\begin{array}{l}i=1,2, \ldots, 4 \\
j=1,2, \ldots, 16 \\
\text { e } x_{i}^{(1)} \text { in the } j^{t h} \\
\text { are referred to }\end{array}$ & (2) \\
\hline 2 & $\begin{array}{l}\text { Generate the firing } \\
\text { strengths of the } j^{\text {th }} \text { fuzzy } \\
\text { rule }\end{array}$ & $y_{i}^{(2)}=w_{i}=\prod_{i} \mu_{A_{i}^{j}}\left(x_{i}^{(1)}\right)$ & $\begin{array}{l}i=1,2, \ldots, 4 \\
j=1,2, \ldots, 16\end{array}$ & (3) \\
\hline 3 & $\begin{array}{l}\text { Normalizes the firing } \\
\text { strengths of each rule }\end{array}$ & $y_{i}^{(3)}=\overline{w_{l}}=\frac{w_{i}}{\sum_{1}^{i} w_{i}}$ & $i=1,2, \ldots, 4$ & (4) \\
\hline 4 & $\begin{array}{l}\text { The output is comprised } \\
\text { of a linear combination of } \\
\text { the inputs multiplied by } \\
\text { the normalized firing } \\
\text { strength } w \\
\text { where } \bar{w}_{i} \text { is the output of la } \\
\text { called consequent paramete }\end{array}$ & $\begin{array}{l}y_{i}^{(4)}=\bar{w}_{i} f_{i}=\bar{w}_{i}\left(c_{1}^{j} x_{1}+c_{2}^{j} x_{2}+c_{3}^{j} x_{3}+c_{4}^{j} x_{4}+c_{5}^{j}\right) \\
\text { er } 3 \text {, and }\left(c_{1}^{j}+c_{2}^{j}+c_{3}^{j}+c_{4}^{j}+c_{5}^{j}\right) \text { denotes a set of unk }\end{array}$ & own parameters & (5) \\
\hline 5 & $\begin{array}{l}\text { Computes the overall } \\
\text { outputs as the summation } \\
\text { of all incoming signals }\end{array}$ & $y_{i}^{(5)}=\sum_{i} \bar{w}_{i} f_{i}$ & $\begin{array}{c}i=1,2, \ldots, 4 \\
j=1,2, \ldots, 16\end{array}$ & (6) \\
\hline
\end{tabular}

ANFIS is trained with a set of input and output data. To reduce the error of the training, during the process of modeling a hybrid learning algorithm combining the gradient descent method and the least squares method is used to tune optimally the linear and nonlinear parameters of the ANFIS. The 
consequent parameters $\left(c_{1}^{j}+c_{2}^{j}+c_{3}^{j}+c_{4}^{j}+c_{5}^{j}\right)$ are optimized by using the least squares method, whereas the premise parameters $a_{i}, b_{i}$, and $c_{i}$ are updated via the gradient descent method.

\subsection{Prediction of time-series}

A time-series is a chronological sequence of observations on a particular variable denoted by $S_{t}=$ $\left\{y_{1}, y_{2}, \ldots, y_{t}\right\}$, in which each observation $y_{t}$ is recorded at a particular time (for $t=1,2, \ldots, n$ ). Prediction of time-series refers to estimate the future values by using a set of regressors or observed values over a suitable time horizon. Time-series prediction is an active area of research due to the variety of applications in financial markets [66, 67], weather forecasting [68-70], among others. Moreover, different researches have demonstrated that ANFIS is adapted for time-series prediction such as Mackey-Glass [58, 60,71], Box-Jenkins [71], Duffing forced-oscillation system [60], wind speed and direction [70], energy market [47] or machinery degradation data [49, 72].

In this paper the prediction of the output voltage of a fuel cell is considered. This physical quantity is represented as a time-series and included into a prediction methodology. This is the central idea presented on next section.

\section{ANFIS-based time-series prognostic}

This section presents an ANFIS-based methodology for prognostic of time-series. The observed values of the series are used to train an ANFIS which models the relationship among the time-series future and previous observed values. As hypothesis to do so, it is considered that the signal can be modeled by a near-periodical time-series. Section 5 of this paper shows how some non-periodical signals could be transformed into near-periodical signals. The proposed methodology is implemented by following the next steps: inputs and output definition, data organization, training and prediction, and finally, performance evaluation.

\subsection{Inputs and outputs definition}

The input of the ANFIS represented by $F$ is a set of $N$ values containing the present-time value and $N-1$ regressors (previous-time values) of the time-series represented by $y(t)$. A time delay represented by $\alpha$ determines the location of the $N-1$ regressors. The output of the ANFIS is a singleton representing the value of the time-series in a near future defined by a time delay represented by $\beta$. The relationship among the inputs and the output is defined by Eq. 7, where the notation $\hat{y}(t)$ is retained for predicted values.

$\hat{y}(t+\beta)=F[y(t-(N-1) \alpha), \ldots, y(t-2 \alpha), y(t-\alpha), y(t)]$

As an example, Fig. 3 illustrates the relationship between the I/O (4 inputs/1 output) and the ANFIS system represented by $F$.

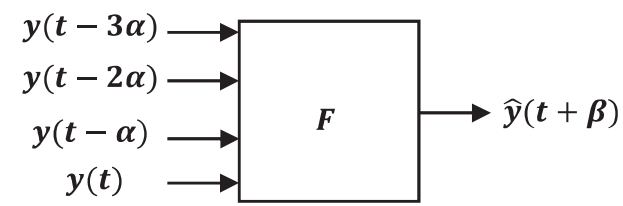

Fig. 3 - Architecture of the ANFIS system with 3 regressors $(N=4)$.

\subsection{Data organization}

Available observed data is divided into two sets, one for training and another for validation. The training values are organized in sets like in Eq. 7. Table 2, shows how data is organized, in this example the signal is sampled from $t=0$ to $t=m$ with a frequency of $1 \mathrm{~Hz}$. It can be observed that the number of data sets used to train the ANFIS is less than the number of observed values. 


Table 2 - Data-set organization for training (UK = Unknown value).
\begin{tabular}{cccccc}
\hline$t$ & $y(t+\beta)$ & $y(t)$ & $\ldots$ & $y(t-N \alpha)$ \\
\hline 0 & $y(\beta)$ & $y(0)$ & - & $U K$ \\
$\vdots$ & - & - & - & - \\
$\alpha$ & $y(\alpha+\beta)$ & $y(\alpha)$ & - & $U K$ \\
$\vdots$ & - & - & - & - \\
$N \alpha-1$ & $y(N \alpha+\beta-1)$ & $y(N \alpha-1)$ & - & $U K$ \\
\hline$N \alpha$ & $y(N \alpha+\beta)$ & $y(N \alpha)$ & - & $y(0)$ \\
$\vdots$ & - & - & - & - \\
$m-\beta-1$ & $y(m)$ & $y(m-\beta-1)$ & - & $y(m-\beta-1-N \alpha)$ \\
$m-\beta$ & $U K$ & $y(m-\beta)$ & - & $y(m-\beta-N \alpha)$ \\
\hline$\vdots$ & - & - & - & - \\
$m$ & $U K$ & $y(m)$ & - & $y(m-N \alpha)$ \\
\hline
\end{tabular}

If raw_data represents the quantity of these observed values, the quantity of exploitable sets to train the ANFIS (trn_data) is defined by Eq. 8.

$t r n \_d a t a=r a w_{-} d a t a-(N-1) \alpha-\beta$

Fig. 4 illustrates the data sets used to train the ANFIS. In this example, the Mackey-Glass (MG) chaotic time-series [73] is sampled in the interval $0<t<100 \mathrm{~s}$ with a frequency of $1 \mathrm{~Hz}$. Here, $r a w_{-}$data $=101, N=3, \alpha=\beta=5$ and trn_data $=86$.

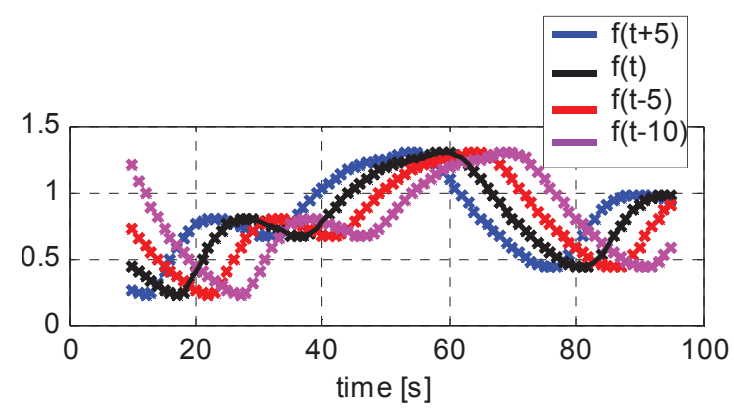

Fig. 4 - Data-set organization for training.

\subsection{ANFIS training and prognostic}

The notation $F$ is retained to represent the input/output relationship of the ANFIS system. The ANFIS is trained using the observed data organized in sets as described in Section 3.2 and the relationship defined in Eq. 7. During training, only observed values of $y(t)$ are considered. The last observed value is represented by $y_{m-1}$, the first predicted value is represented as $y_{m}$. The horizon of prediction represented by $\mathrm{h}$ determines the quantity of values to predict and then when the algorithm finishes. Multi-steps ahead prediction (MSP) modeling by using neural networks can be achieved in different manners. This is not addressed in this paper, but one can refer to [74] for more details. Here, MSP are performed by using an iterative approach. This approach uses a single model that is tuned to perform a one-step ahead prediction $\hat{y}_{t+1}$. The estimated values are used as one of the regressors of the model to estimate next time outputs. The operation is repeated until the estimation of the value of the signal at the horizon of prediction $\hat{y}_{t+h}$. This iterative procedure is illustrated in Fig. 5. 


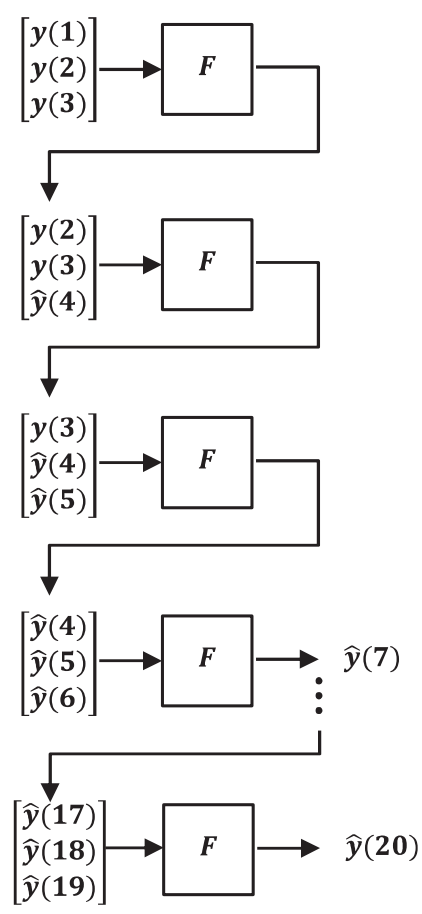

Fig. 5 - Iterative structure example with $(N=3), \alpha=\beta=1, M F=3$ and $h=17$.

After few iterations the predictions uses predicted (not observed) values and the equation is represented as in Eq. 9. The principal drawback of this approach is the propagation of the error: the accuracy decreases as the length of the prediction horizon increases.

$\hat{y}(t+\beta)=F[\hat{y}(t-(N-1) \alpha), \ldots, \hat{y}(t-2 \alpha), \hat{y}(t-\alpha), \hat{y}(t)]$

Due to their generalization capabilities, Gaussian antecedent fuzzy sets are generally assumed to define the regions of fuzzy rules in which the local linear sub-models are valid $[53,58,60,65]$.

A priori, it is expected than an increase of the number of MFs could improve the quality of the prediction. However, this also implies an increase in the complexity to train the ANFIS and therefore the computing-time. The same analysis applies to the number of inputs, moreover according to Eq. 8, an augmentation in $N$ implies less exploitable data sets to train the ANFIS. The influence of $\alpha$ and $\beta$ is more difficult to define, and it will be shown that its selection depends on the specific time-series, and that there is dependence between the selection of $\alpha, \beta$ and the number of inputs. ANFIS parameters selection issue is deeper studied in Section 4.

\subsection{Performance evaluation}

The quality of the prediction is evaluated in accuracy and speed. The ANFIS is expected to give a good solution, able for implementation in real-time applications, i.e. related to the time needed to process a result under a very tight deadline facilitating decision making. The challenge is to define the parameters of the ANFIS: the number of inputs $N$, the time delays between successive observed values $\alpha$ and $\beta$ and the number of membership functions whilst having a good balance between quality and speed.

The performance of the prediction is quantified by using the following standard statistical criteria: the Root Mean Square Error (RMSE), the Mean Absolute Percent Error (MAPE) and the coefficient of determination $\left(\mathrm{R}^{2}\right)$ as classically done in literature $[75,76]$. These criteria are defined by Equations 10 , 11 and 12 respectively where $\hat{y}_{i}$ represents the predicted values, $y_{i}$ the observed values, $\bar{y}_{i}$ the average of the observed set, and $m$ is the number of observed values. 
$R M S E=\sqrt{\frac{1}{m} \sum_{i=1}^{m}\left(\hat{y}_{i}-y_{i}\right)^{2}}$

MAPE $=\frac{1}{m} \sum_{i=1}^{m} \frac{\left|\hat{y}_{i}-y_{i}\right|}{\left|y_{i}\right|} * 100$

$R^{2}=1-\frac{\sum_{i=1}^{m}\left(y_{i-} \hat{y}_{i}\right)^{2}}{\sum_{i=1}^{m}\left(y_{i}-\bar{y}_{i}\right)^{2}}$

RMSE and MAPE are positive numbers, a perfect prediction gives values of RMSE and MAPE equals to zero. $R^{2}$ is a positive number between zero and one. A value for $R^{2}$ close to one shows a good fit of prediction model and a value close to zero presents a poor fit [75]. Given two sets of parameters providing (almost) the same accuracy in prediction, the faster could be the better adapted to perform real-time implementation of the methodology.

\section{Prediction of Mackey-Glass temporal series}

The methodology presented in Section 3 is illustrated by performing the prediction of the MG chaotic time-series defined in Eq. 13. The MG time delay differential equation [73] was first proposed for modeling white blood cell production in a human body. The prediction of this time-series is a benchmark problem widely used in the literature as reference to evaluate the performance of prediction tools [58-60].

$\frac{d x(t)}{d t}=\frac{a x(t-\tau)}{1+x^{c}(t-\tau)}-b x(t)$

As explained in precedent section, the challenge is to identify the ANFIS parameters: number of inputs $N$, the time delays between successive values $\alpha$ and $\beta$ and number of membership functions, which better predict the time-series. To do so, multiple sets of parameters $(N, M F, \alpha)$ are considered to predict the time-series. Moreover, two set of parameters $(a, b, c, \tau$ and $x(0))$ are considered to evaluate if a unique set of ANFIS parameters can be used to predict different time-series.

\subsection{Validation}

The first time-series to evaluate the ANFIS is shown in Fig. 6. The values of the time-series are organized as explained in Section 3.2. The time-series are divided into two sets of values. The first set $\left[t_{0}, t_{1}\right]$ is used to train the ANFIS and the second set $\left[t_{1}, t_{1}+h\right]$ to validate the prognostic.

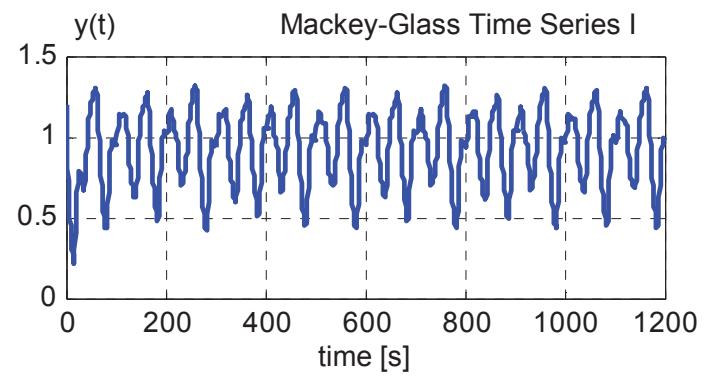

Fig. 6 - MG time-series, $a=0.2, b=0.1, c=10, \tau=17, x(0)=1.2$.

\subsubsection{Results}

In order to identify the best sets of parameters, multiple ANFIS are trained using all the combinations of the following parameters: $M F(2,3$ and 4), $N(3,4$ and 5) and $\alpha(3,6$ and 9). The training is done with the following values, $t_{0}=0 \mathrm{~s}, t_{1}=500 \mathrm{~s}$ and $h=700$. Table 3 summarizes the best prediction results $\left(\mathrm{R}^{2}>0.9\right)$. Fig. 7 shows the predictions obtained using the best set of parameters. 


\begin{tabular}{|c|c|c|c|c|c|c|}
\hline \multirow{2}{*}{$N$} & \multirow{2}{*}{$\alpha$} & \multirow{2}{*}{$M F s$} & \multicolumn{3}{|c|}{ Prediction Error } & \multirow{2}{*}{$\begin{array}{c}\mathrm{CT} / \mathrm{CT}_{\mathrm{N}=4, \alpha=6, \mathrm{MFs}=3} \\
\text { (best performance set) }\end{array}$} \\
\hline & & & RMSE & MAPE [\%] & $\mathrm{R}^{2}$ & \\
\hline 4 & 6 & 3 & 0,0435 & 3,7398 & 0,9636 & 1 \\
\hline 5 & 9 & 3 & 0,0497 & 3,5579 & 0,9525 & 31 \\
\hline 5 & 6 & 4 & 0,0567 & 4,0210 & 0,9382 & 735 \\
\hline 5 & 6 & 3 & 0,0576 & 4,3153 & 0,9362 & 31 \\
\hline 4 & 6 & 4 & 0,0591 & 4,1141 & 0,9327 & 24 \\
\hline 5 & 6 & 2 & 0,0599 & 4,4278 & 0,9310 & 0.2 \\
\hline
\end{tabular}

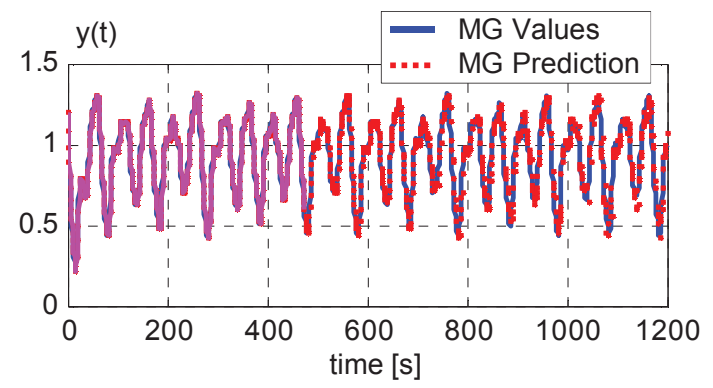

Fig. 7 - MG Time-series I Prediction, $N=4, M F s=3, \alpha=6, t_{0}=0, t_{1}=500, h=700$.

\subsubsection{Parameter selection}

A priori, it is expected than an increase of the number of $M F s$ could improve the quality of the prediction. However, this also implies an increase in the complexity to train the ANFIS and therefore the computing-time. The same analysis applies to the number of inputs, moreover according to Eq. 8, an increase in $N$ implies less exploitable data sets to train the ANFIS. The influence of $\alpha$ and $\beta$ is more difficult to define, and it will be shown that its selection depends on the specific time-series, and that there is dependence between the selection of $\alpha, \beta$ and the number of inputs. Due to their generalization capabilities, Gaussian antecedent fuzzy sets are generally assumed to define the regions of fuzzy rules in which the local linear sub-models are valid $[53,58,60,65]$. As the computing time to train the ANFIS depends on the number of fuzzy rules, increasing $N$ and $M F$ corresponds to an increased computing time. Nevertheless it does not necessarily increase the quality of the prediction. This can be explained as an accurate model can be useful to represent periodical functions, but not necessarily improves the prediction of non-periodical functions.

The two best sets of parameters provide almost the same accuracy in prediction $\left(R^{2}>0.95\right)$, however the set $(\mathrm{N}=4, \mathrm{MF}=3, \alpha=6)$ is more than 30 times faster in computing time and then it is better adapted for real-time implementation. It can be considered that prediction of time-series could be performed using 4 inputs and $3 M F s$. To evaluate this hypothesis, in section 4.3, a second MG time-series is predicted using these parameters.

At this point it is difficult to conclude about the selection of $\alpha$ and then an additional evaluation of this parameter is performed by training additional ANFIS $(N=4$ and $M F=3)$, while $\alpha$ varies from 1 to 20 . The results ( $\mathrm{R}^{2}, \mathrm{MAPE}$ and RMSE) are shown in Fig. 8 . Here $\alpha=6$ gives the best performance prediction. This can be explained because the ANFIS is trained by using the previous $18 \mathrm{~s}((N-1)$. $\alpha)$ of the time-series, and this value is very close to the time constant of the time-series $(\tau=17 \mathrm{~s})$. The training uses one and only one time constant period of the signal and then the ANFIS is able to better represent the signal. The selection of $\alpha$ is studied again in Section 4.3. 

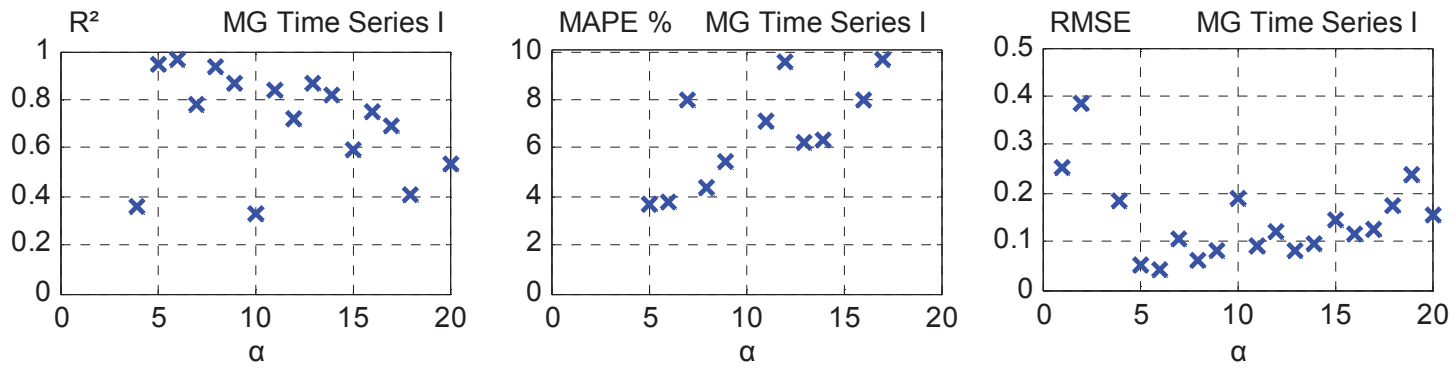

Fig. 8 - Prediction performances vs alpha $(\mathrm{N}=4, \mathrm{MF}=3)$.

\subsection{Horizon of prediction}

The prediction horizon $h$ could be adapted to short, medium or long-term prediction. However, this depends on the quantity and quality of data to train the ANFIS. To evaluate the necessary amount of data, ANFIS are trained using different values of training data. Figures 9 and 10 present predictions of the MG time-series performed using ANFIS and trained with $t_{1}=100 \mathrm{~s}$ and $t_{1}=250 \mathrm{~s}$ respectively. In this example, the horizon of prediction is imposed as the quantity of data. As expected, the quality of the prediction increases with the quantity of data, however the ANFIS trained with $t_{1}=250 \mathrm{~s}$ represents with relatively low error the MG series. The first ANFIS is trained with less than one period and then the results are not accurate at all, the second ANFIS is trained with data from two periods, and the results are more accurate. The ANFIS trained with $t_{1}=500 \mathrm{~s}$ (Section 4.1) shows results with high quality. Figures 11,12 and 13 illustrate the evolution of the error ( $\mathrm{R}^{2}$, MAPE and RMSE) regarding the horizon of prediction and the quantity of data used to train the ANFIS. As expected the quality of prediction improves while increasing the training data, moreover the predictions at long horizon of prediction are only possible with relatively high data.

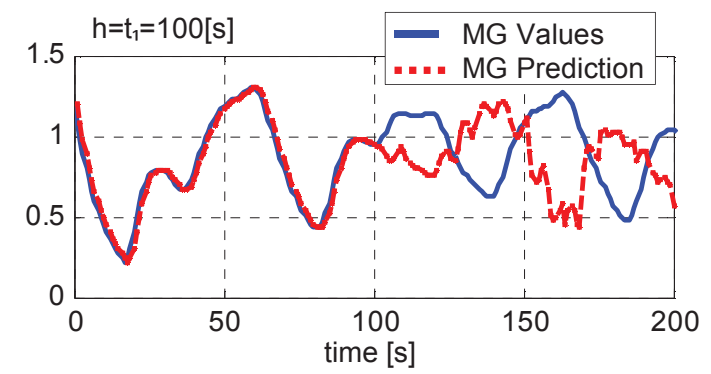

Fig. 9 - Mackey-Glass time-series I $t_{0}=0, t_{1}=100, h=100$.

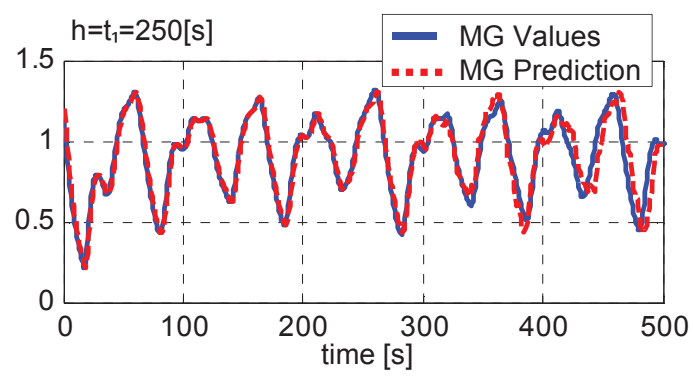

Fig. 10 - Mackey-Glass time-series I $t_{0}=0, t_{1}=250, h=250$.
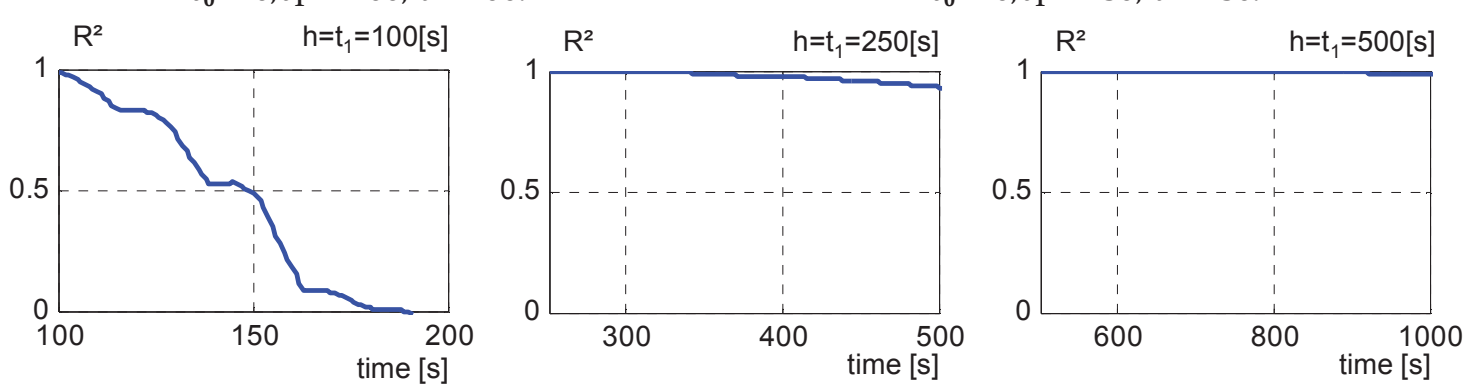

Fig. 11 - MG time-series prediction, $\mathbf{R}^{2}$ vs horizon of prediction. 

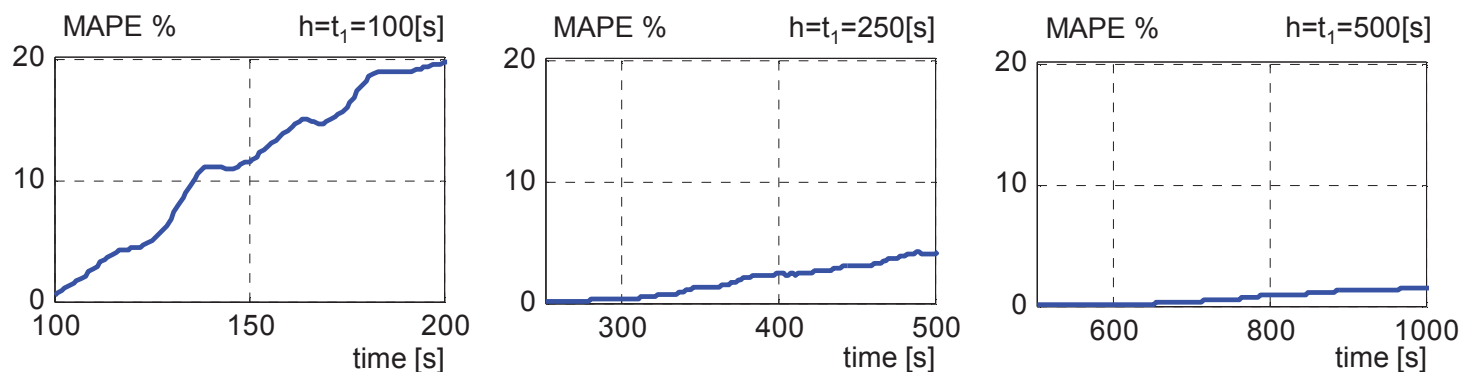

Fig. 12 - MG time-series prediction, MAPE vs horizon of prediction.
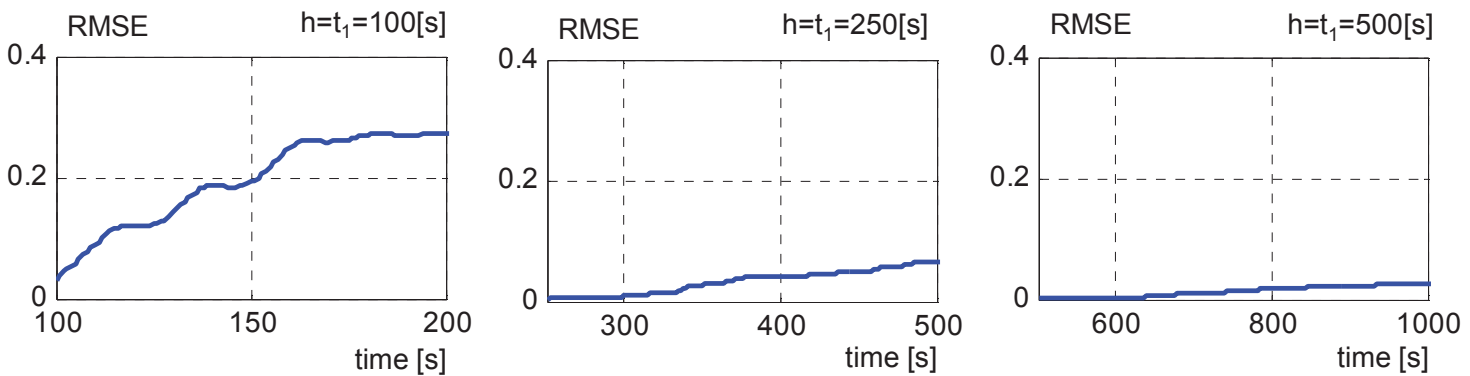

Fig. 13 - MG time-series prediction, RMSE vs horizon of prediction.

\subsection{Evaluation using a second time-series}

Using the results obtained in Section 4.1, it can be inferred that to perform ANFIS prediction of a near periodical time-series, accurate results will be found by training the ANFIS with 4 inputs and $3 M F S$. The best value of $\alpha$ depends on the time constant of the time-series. To evaluate this hypothesis, a second MG time-series is considered and is illustrated in Fig. 14. Fig. 15 presents the best prediction obtained with $N=4, M F=3$ and $\alpha=14$. Figure 16 presents the error depending on $\alpha$. Values of alpha 13 and 14 enables the better performance predictions, in this case the ANFIS is trained by using the previous 39 and 42 s of the time-series, and this value is very close to the time constant of the timeseries $(\tau=40 \mathrm{~s})$. Predictions obtained with ANFIS trained using other values of $\alpha$ have very bad (very high errors) and the axes of Figure 16 are limited to present only reasonable errors.

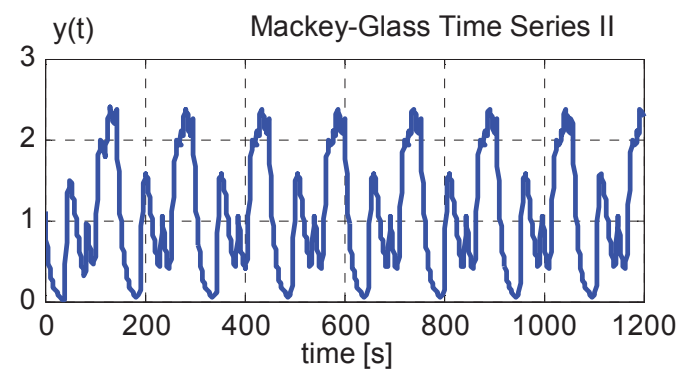

Fig. 14 - MG time-series II. $a=0.3, b=0.08, c=15$, $\tau=40, x(0)=1.1$.

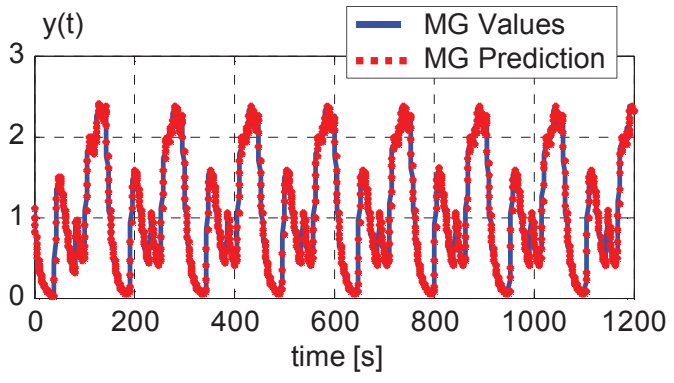

Fig. 15 - MG time-series II. $N=4, M F s=3, \alpha=14$ $t_{0}=0, t_{1}=500, h=700$. 

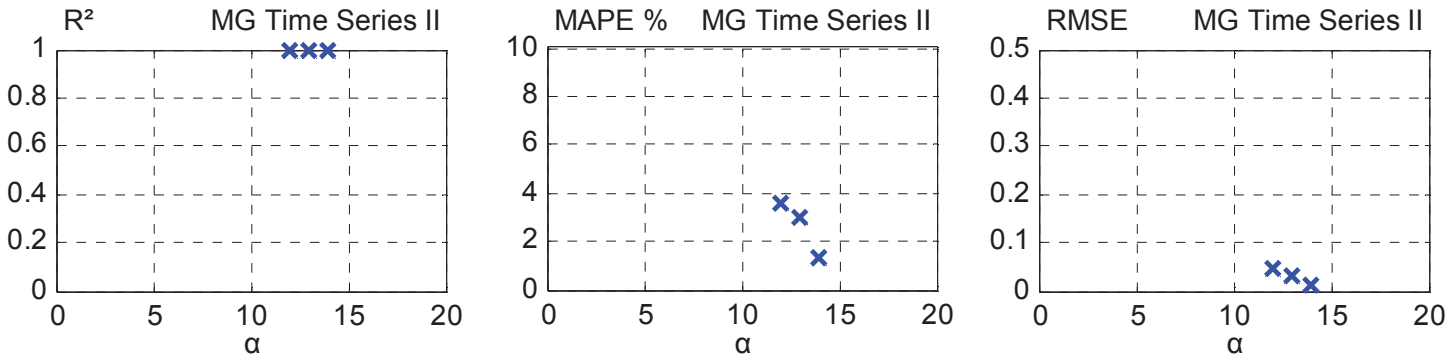

Fig. 16 - Error measurements: Mackey-Glass Time-series II (Axes limited to show only the best results).

As a conclusion of this section, ANFIS are appropriated to predict time-series. The results obtained with 4 inputs and $3 M F S$ appear to be the best compromise quality between solution and computing time, at least for the considered Mackey-Glass series. The best value of $\alpha$ strongly depends on the time-series time constant.

\section{Fuel cell degradation prediction}

\subsection{Fuel cell data acquisition}

This section deals with the prediction of the degradation during nominal operating condition of a PEM fuel cell stack. As the stack voltage is the simplest indicator of the state-of-health and performance of the FCS, the methodology is based on the prediction of the temporal output voltage variation. To do so, the methodology introduced in previous sections is considered on the prediction of the temporal variation in the output voltage of a fuel cell measured during a long term operation. To evaluate and validate the proposed methodology experimental data are considered.

The data is issue of long-term tests performed on two PEM fuel cell stacks. Two 5 cell-350 $\mathrm{cm}^{2}$ active surface stacks are evaluated under different scenarios. The following conditions are maintained over periods of 1000 hours of continuous operation. The first stack is operated at a constant load current of $250 \mathrm{~A}$, a temperature of $70{ }^{\circ} \mathrm{C}$, an absolute pressure of $1600 \mathrm{mbar}$ and Anode and Cathode Stoichiometry Factors $\mathrm{SFC}=\mathrm{SFA}=2$. The second stack is operated under similar conditions but incorporating a periodical perturbation in the current: a $5 \mathrm{kHz}$ triangular signal with amplitude peak to peak $10 \%$ of the rated current. This type of stress is closer to the experimental conditions generated by connecting the fuel cell to a static DC/DC converter. The reader is addressed to [77] for a detailed description of the experimental set up.

The experimental setup allows continuously measuring electrical, fluidic and thermal parameters. Moreover, polarization curves and impedance spectra measurements are periodically performed. Stack voltages of both fuel cell stacks are illustrated in Figures 17 and 18.

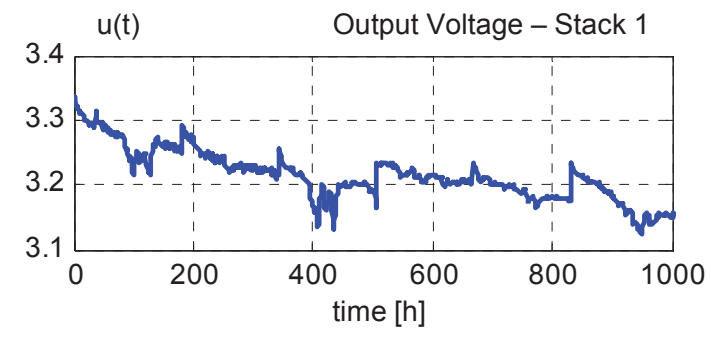

Fig. 17 - Fuel cell stack 1 output voltage.

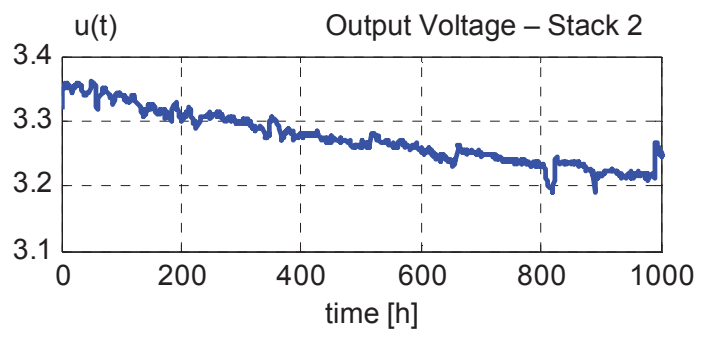

Fig. 18 - Fuel cell stack 2 output voltage.

\subsection{Simplification hypotheses}

In the developed ANFIS, the voltage variations induced by degradation effects of two PEMFC stacks operated up to 1000 hours at nominal operating conditions were analyzed. The prediction model was constructed based on the following hypotheses: (i) aging processes are irreversible degradations; (ii) the stack is used under constant current solicitation and in stable environmental conditions; (iii) 
electrical, fluidic and thermal parameters are controlled: solicitation is realized at the nominal operating point.

Most of degradation processes, reversible or not, have an impact on the output voltage which it is always a monitored control variable. Furthermore, voltage measurements are non-intrusive, cheap and easy to implement. However, by using voltage measurements as inputs on the prediction model, the results will always predict a horizontal line. Voltage degradation presents a slow evolution in time, it can be considered as a time series to provide accurate predictions. The output voltage of a fuel cell stack cannot be considered as a quasi-periodical time-series because it has a tendency to decrease with time and operation. This paper proposes to consider the temporal variation of the output voltage as a quasi-periodical time-series. If this variation can be predicted using the proposed methodology, then the output voltage can be reconstructed using an integrator. However, to do so the structure of the ANFIS introduced on Section 3 has to be slightly modified as shown in Section 5.3. This section also proposes a method to reduce the error in the predictions caused for external perturbations in the output voltage such as transients when the fuel cell is started. It is proposed to split the signal in two components: one for the voltage due to normal operation and a second one caused by external perturbations.

Experimentally, the voltage is measured with a frequency of $1 \mathrm{~Hz}$; however, to train the ANFIS the observations are done with one hour intervals, sampling was defined with the aim of reducing estimation time, this by reducing the number of iterations necessary to meet the convergence criteria and, consequently to save computational cost. Considering the low rate of degradation of a fuel cell (typically few $\mu \mathrm{V} /$ cell/hour), the subtracted sets was small enough to maintain representative information from the original data.

\subsection{Inputs and outputs definition}

Eq. 7 is not adapted to train the ANFIS using the output voltage variation and then it is modified as shown in Eq. 14. As the output voltage has a tendency to decrease the voltage drop is considered as a positive variation, and in this equation the term in the left represents the voltage drop in the future $\beta$ seconds, the terms in the right the voltage drop in the past $(N-1) \alpha, \ldots, \alpha$ hours.

$\hat{u}(t+\beta)-u(t)=F[u(t)-u(t-(N-1) \alpha), \ldots, u(t)-y(t-\alpha), u(t)-y(t)]$

Fig. 19 describes the modified input/output structure used to predict the voltage variation. In this figure the ANFIS uses 4 inputs and 4 regressors $(\mathrm{N}=$ regressors $=4)$.

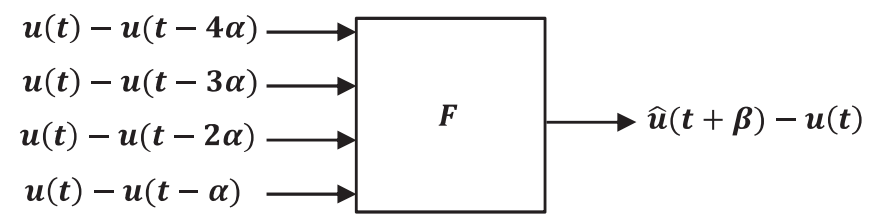

Fig. 19 - Modified I/O architecture of the ANFIS.

\subsection{Results}

Following the results of Section 4, ANFIS are trained using 3 MFs and 4 inputs. Due to the lack of knowledge about the time constant of the signal, in order to find the best value of $\alpha$, ANFIS are trained with multiple values of $\alpha$. Figures 20 and 21 present the results of this analysis done using the first 500 hours to train the system. As it can be seen, values of $\alpha=4$ and 3 (hours) represent in both cases the best performance predictions.

Figures 22 and 23 present the predictions for fuel cell stacks 1 and 2 respectively. The predictions are performed with ANFIS trained with 4 inputs, 3 MFs and 3 hours intervals measures of voltage. The accuracy of the prediction is much lower than in previous examples (Mackey-Glass time-series). Nevertheless, as shown in Figures 22 and 23 the prediction follows the real tendency. 

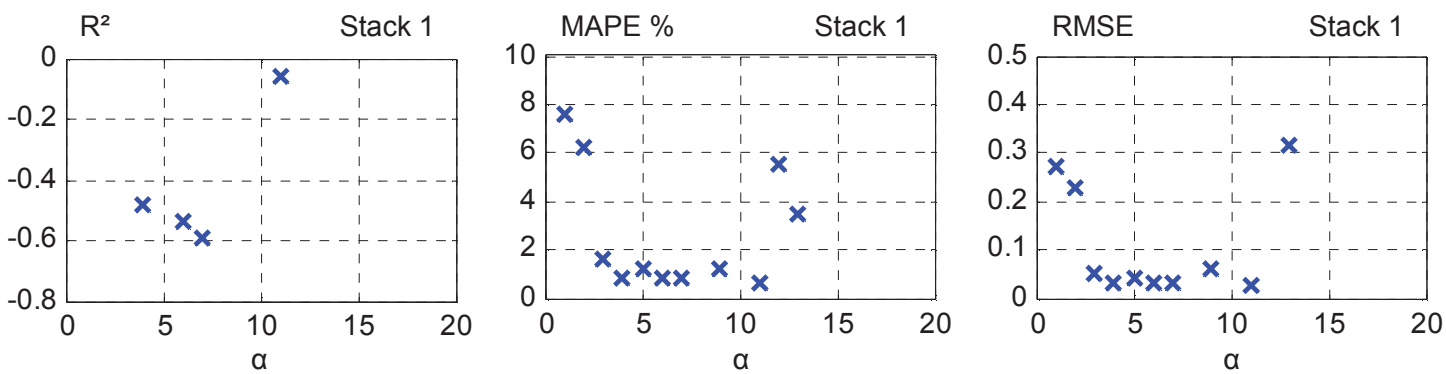

Fig. 20 - Stack 1: Prediction performances vs alpha $(\mathrm{N}=4, \mathrm{MF}=3)$.
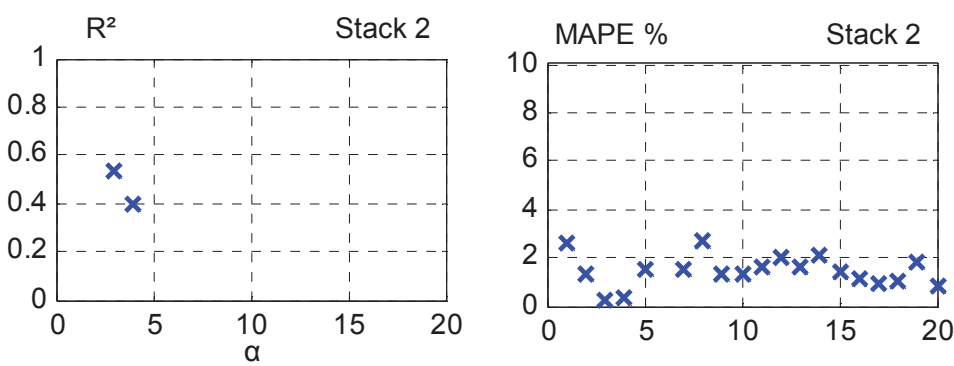

RMSE

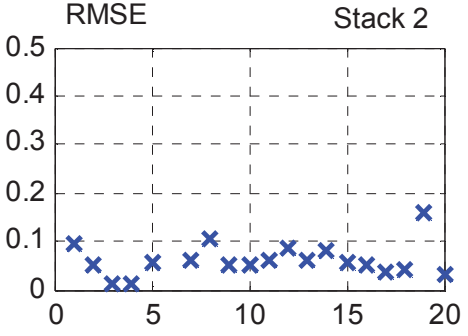

Fig. 21 - Stack 2: Prediction performances vs alpha $(\mathrm{N}=4, \mathrm{MF}=3)$.

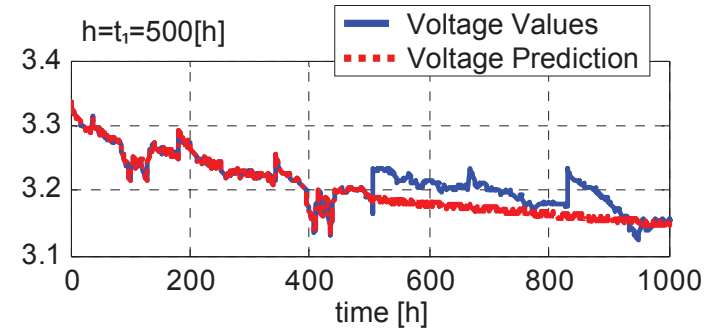

Fig. 22 - Output voltage predictions: Stack 1, $N=4, M F s=3, \alpha=4, h=t_{1}=500 s$.

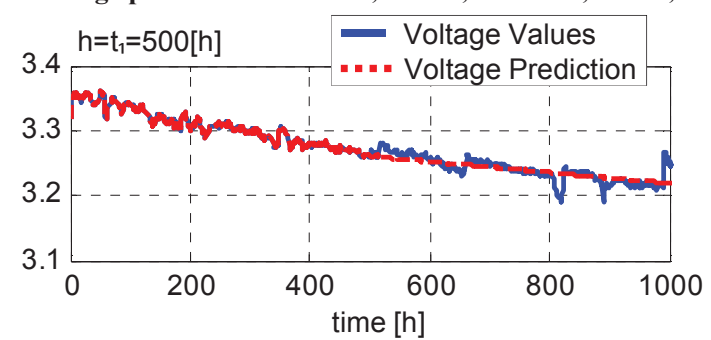

Fig. 23 - Output voltage predictions: Stack 2.

Figures 24 to 29 show the performance of the prediction when different training data (100, 250 and 500 hours) are considered. The quality of the prediction is very low when few data are used to train the system, however reasonably good predictions can be obtained with high number of data. The horizon of prediction is highly reduced compared to Mackey Glass time-series. 

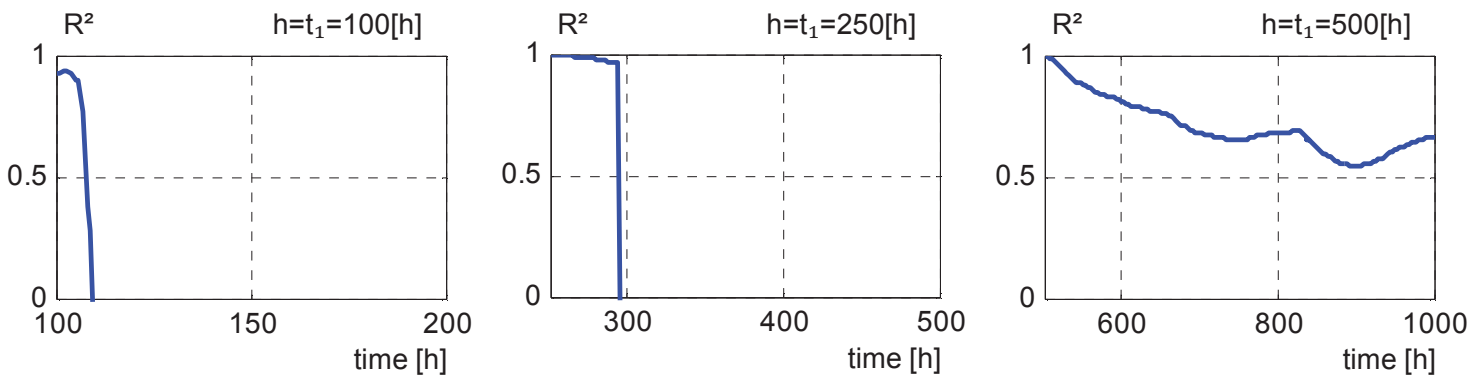

Fig. 24 - Stack $1, R^{2}$ vs horizon of prediction.
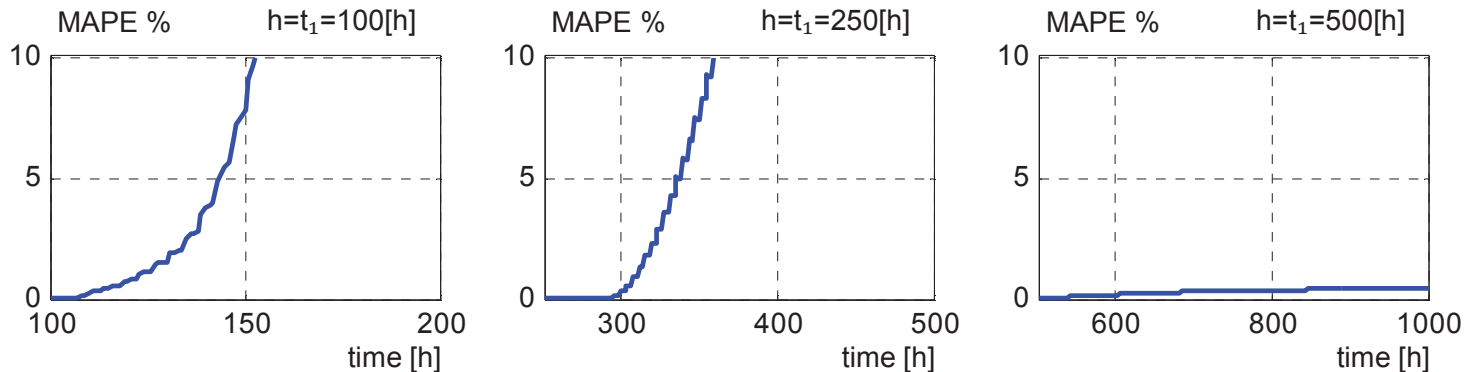

Fig. 25 - Stack 1, MAPE vs horizon of prediction.
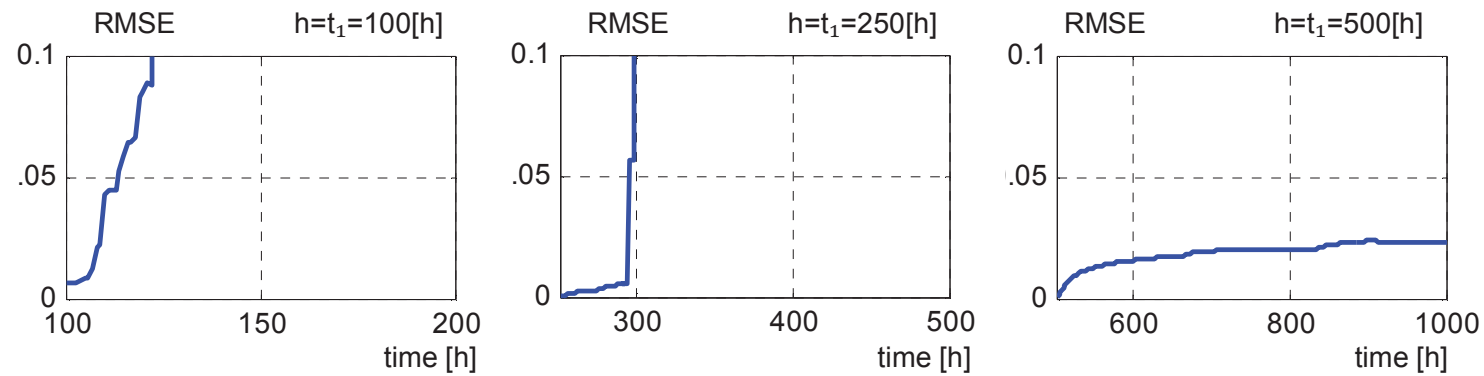

Fig. 26 - Stack 1, RMSE vs horizon of prediction.
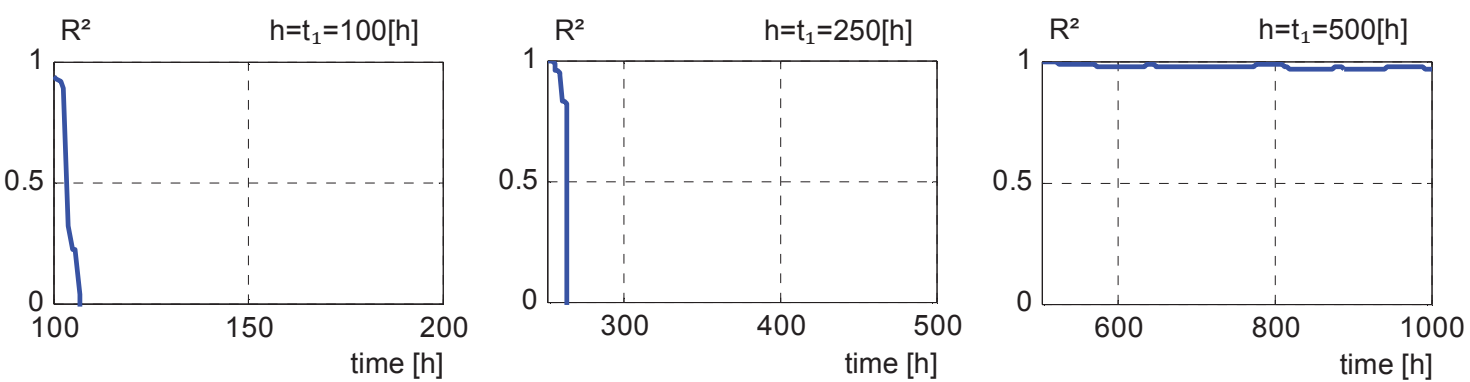

Fig. 27 - Stack $2, \mathbf{R}^{2}$ vs horizon of prediction.
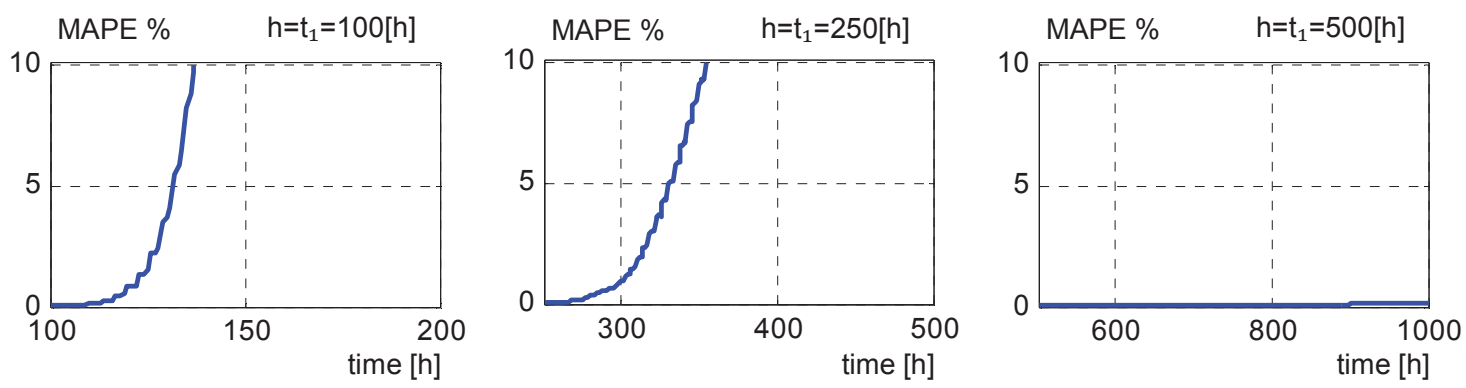

Fig. 28 - Stack 2, MAPE vs horizon of prediction. 

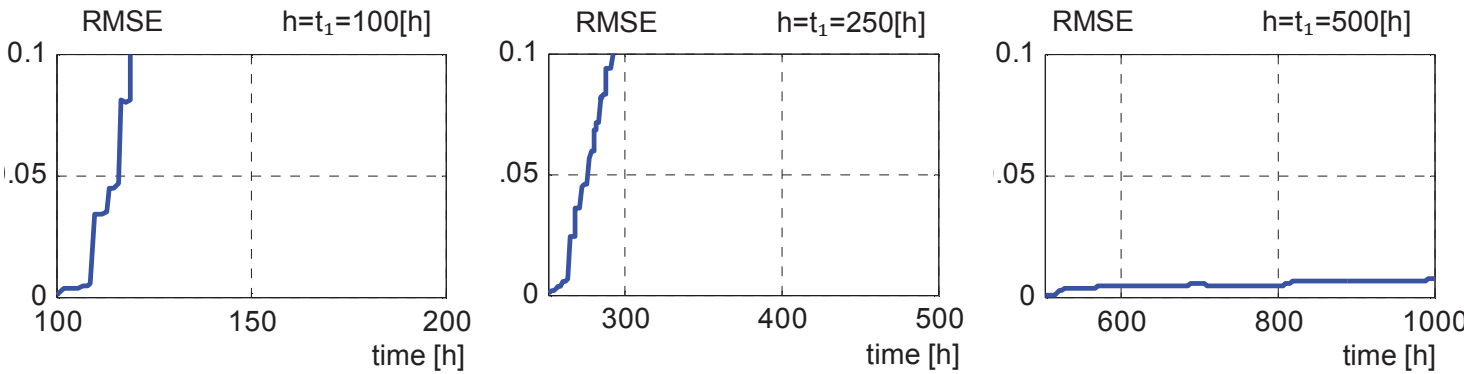

Fig. 29 - Stack 2, RMSE vs horizon of prediction.

\subsection{Split signal prediction}

One of the principal challenges is that abrupt changes in the output voltage (i.e. stop procedures, variation in the operating conditions, polarization curves or impedance spectra measurements that are experimentally performed over time to estimate the $\mathrm{SoH}$ of the stack) cannot be predicted. As hypothesis to face this challenge, it is considered that during normal operation the voltage rate of change $(\mathrm{V} / \mathrm{s})$ remains between limits and abrupt perturbations can be identified and then not considered to train the ANFIS.

This research proposes to split the voltage signal in two components: a component due to normal operation voltage and a component due to external perturbations. The parameters used to split the signal are the Arithmetic Mean $(A M)$ and the standard deviation $(\sigma)$ of the voltage change between successive voltage measures. If the change in two successive measures is greater than the $A M \pm 3 \sigma$, then it is considered as an external perturbation (in a normal distribution $99.7 \%$ of the values lie within 3 standard deviations of the mean). The voltage signal is split as shown in Figure 30. The ANFIS is trained using the "normal operation" voltage. In the framework of the PHM methodology this step is performed by the data preprocessing module.

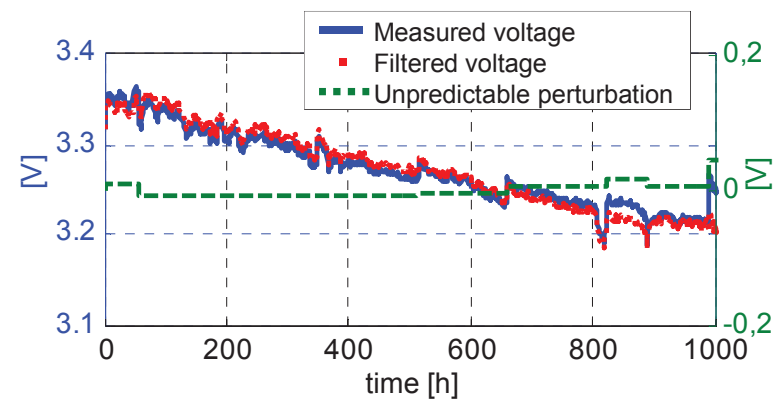

Fig. 30 - Split voltage signal.
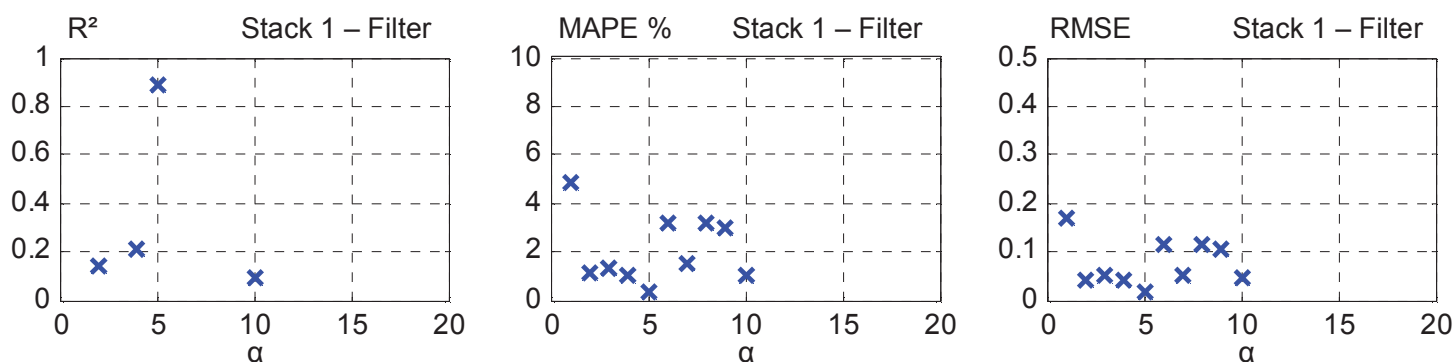

Fig. 31 - Stack 1: Prediction performances vs alpha $(\mathrm{N}=4, \mathrm{MF}=3)$. 

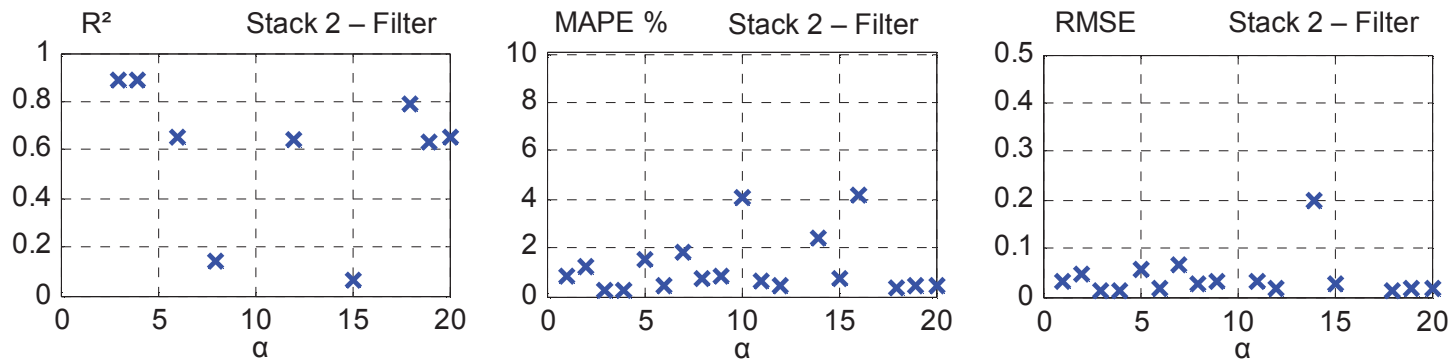

Fig. 32 - Stack 2: Prediction performances vs alpha $(\mathrm{N}=4, \mathrm{MF}=3)$.

Figures 33 and 34 show the best predictions obtained with $\alpha=5$ hours for stack 1 and $\alpha=4$ hours for stack 2 . These values of $\alpha$ were obtained after the same analysis explained in previous sections. Figures 35 to 40 show the performance of the prediction for different values of training data. It can be observed that the performances are highly improved when the voltage signal is split. Moreover, with this improved method good quality predictions are obtained using less training data.

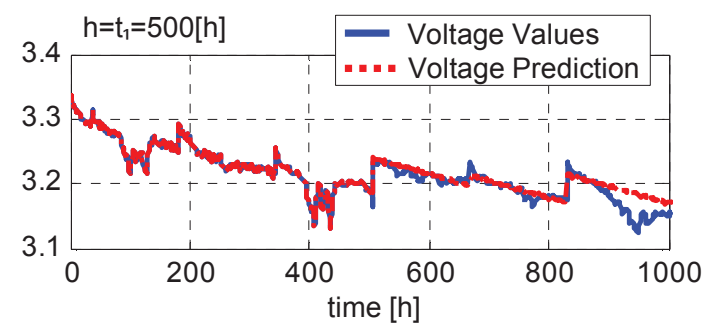

Fig. 33 - Output voltage predictions - Stack 1 Filter, $N=4, M F s=3, \alpha=5$

a) $h=t_{1}=100 \mathrm{~s}$, b) $h=t_{1}=250 \mathrm{~s}$, c) $h=t_{1}=500 \mathrm{~s}$.

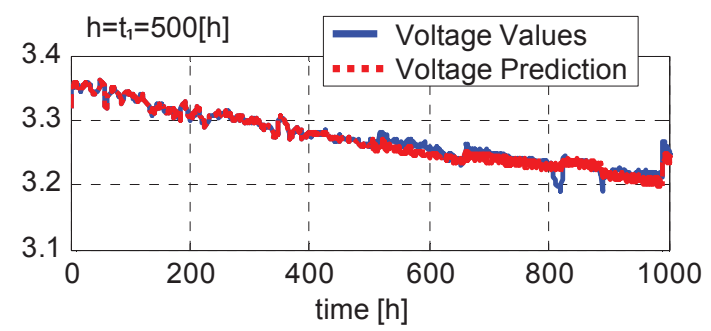

Fig. 34 - Output voltage predictions - Stack 2 Filter, $N=4, M F s=3, \alpha=4$

a) $h=t_{1}=100 \mathrm{~s}$, b) $\left.h=t_{1}=250 \mathrm{~s}, \mathrm{c}\right) \mathrm{h}=t_{1}=500 \mathrm{~s}$
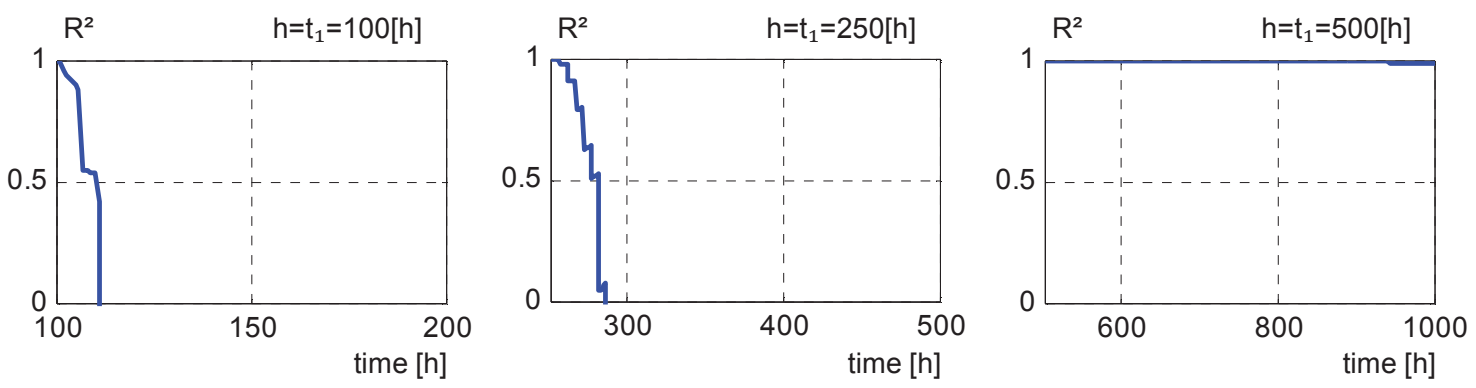

Fig. 35 - Stack 1 Filter, $R^{2}$ vs horizon of prediction. 

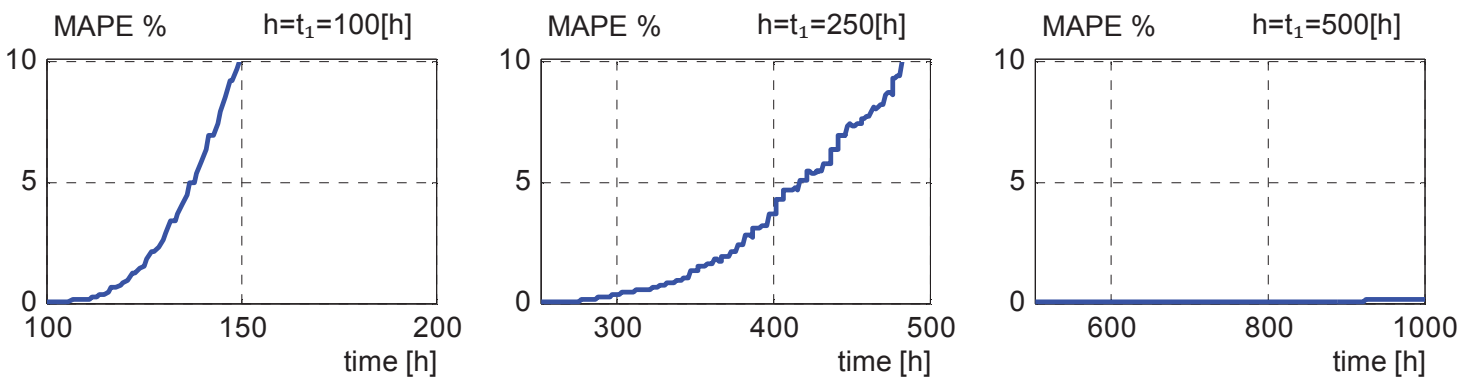

Fig. 36 - Stack 1 Filter, MAPE vs horizon of prediction.
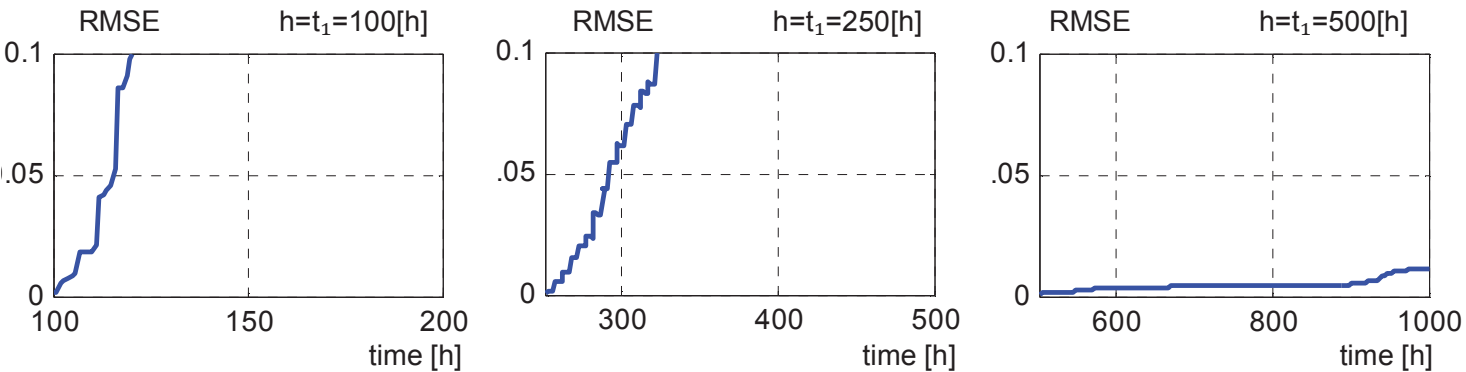

Fig. 37 - Stack 1 Filter, RMSE vs horizon of prediction.
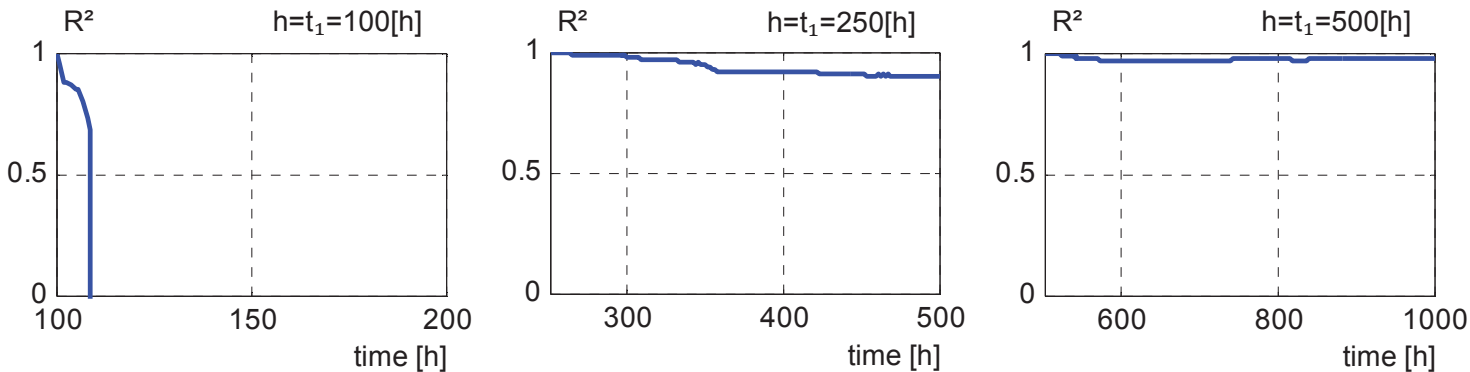

Fig. 38 - Stack 2 Filter, $R^{2}$ vs horizon of prediction.
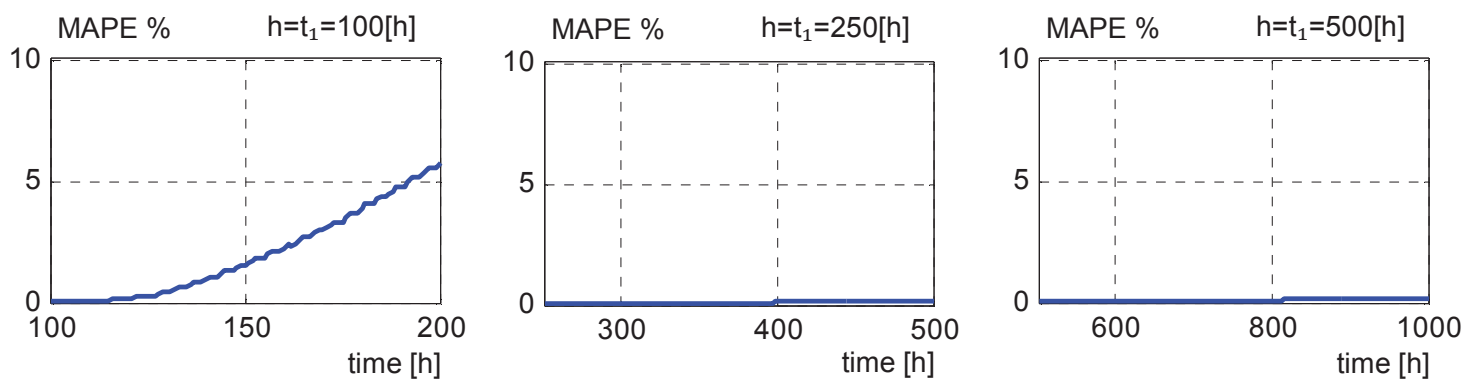

Fig. 39 - Stack 2 Filter, MAPE vs horizon of prediction.
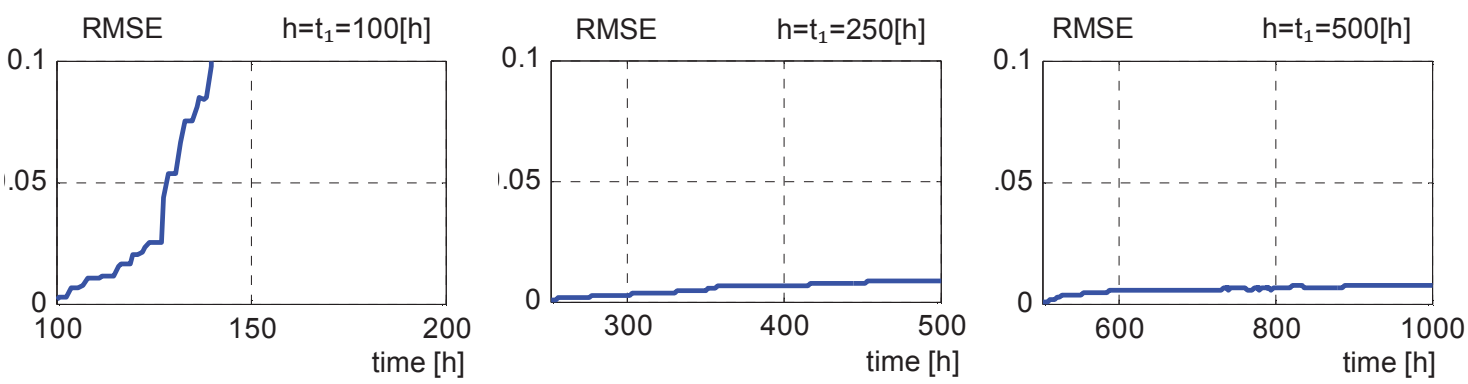

Fig. 40 - Stack 2 Filter, RMSE vs horizon of prediction. 
Table 4 - Best results summary for Stack Voltage prediction. CT= Computing Time.

\begin{tabular}{|c|c|c|c|c|c|c|c|}
\hline & \multirow{2}{*}{$N$} & \multirow{2}{*}{$\alpha$} & \multirow{2}{*}{$M F s$} & \multicolumn{3}{|c|}{ Prediction Error } & \multirow{2}{*}{$\mathrm{CT}[\mathrm{s}]$} \\
\hline & & & & RMSE & MAPE [\%] & $\mathrm{R}^{2}$ & \\
\hline \multirow[t]{2}{*}{ Stack 1} & 4 & 11 & 3 & 0.0263 & 0.6372 & -0.0606 & 6.5007 \\
\hline & 4 & 4 & 3 & 0.0317 & 0.8579 & -0.4848 & 6.7360 \\
\hline \multirow[t]{2}{*}{ Stack 1 Filter } & 4 & 5 & 3 & 0.0158 & 0.3467 & 0.8851 & 6.5356 \\
\hline & 4 & 4 & 3 & 0.0414 & 1.0367 & 0.2113 & 6.6210 \\
\hline \multirow[t]{2}{*}{ Stack 2} & 4 & 3 & 3 & 0.0123 & 0.2810 & 0.5335 & 6.6389 \\
\hline & 4 & 4 & 3 & 0.0140 & 0.3197 & 0.3946 & 7.7040 \\
\hline \multirow[t]{2}{*}{ Stack 2 Filter } & 4 & 4 & 3 & 0.0100 & 0.2455 & 0.8891 & 6.8208 \\
\hline & 4 & 3 & 3 & 0.0102 & 0.2372 & 0.8863 & 6.8503 \\
\hline
\end{tabular}

\section{Conclusion}

This paper introduces an Adaptive Neuro-Fuzzy Inference System (ANFIS)-based methodology for prediction of time-series. The paper studies the architecture and the parameter selection of the ANFIS prediction system, it is done by considering not only the accuracy of the system but also its ability to be implemented into a real-time approach. The paper also proposes to split the signal in two components one due to normal operation and a second caused by external perturbations. This splitting allows reducing the error in the predictions caused by external perturbations (e.g. prediction of the fuel cell output voltage such as transients when the fuel cell is started).

The methodology is evaluated by predicting the voltage output variation in a fuel cell stack under constant operation during a long term operation test. Results show that ANFIS is well adapted to prediction of time-series and particularly to predict loss of performance caused by degradation in fuel cell systems. Simulations results reveal that the obtained ANFIS model can efficiently predict the behavior of the PEM fuel cell. The ANFIS-based methodology is a soft computing approach that provides an excellent platform for PHM of complex and non-linear systems such as fuel cells. Specifically, such an approach does not require advanced physical modeling and is easy to implement and tune. Nevertheless, in ANFIS, the complexity of the training phase is directly dependent on the amount of experimental data and the number and the choice of parameters considered. An accurate approach combines a very low computational cost while keeping a competitive performance in terms of convergence speed, which is suitable for on-line uses.

Further work has to be addressed to propose a robust prognostic tool to estimate the RUL in the fuel cell, with potential targets of reconfiguration control and/or preventive maintenance. The approach considered in this paper to predict the performance loss in FCS is based on the output voltage variation because it is the simplest indicator about its $\mathrm{SoH}$. This enables estimating the degradation but not identifying the failure or degradation modes. For this reason and considering further research, it could be useful to integrate new parameters taking into account operating condition variations (such as start/stop cycling, dynamics loads ..) and changing environmental conditions suffered in a real transport application, and more information such as EIS or polarization curves into the PHM process.

\begin{tabular}{|ll|}
\hline Acronyms \\
AM & Arithmetic Mean \\
ANN & Artificial Neural Networks \\
ANFIS & Adaptive Neuro-Fuzzy Inference System \\
FCS & Fuel Cell System \\
FL & Fuzzy Logic \\
MAPE & Mean Absolute Percent Error \\
MF & Membership Functions \\
MG & Mackey Glass \\
MSP & Multi-steps ahead prediction \\
PEMFC & Proton Exchange Membrane Fuel Cells \\
PHM & Prognostics and Health Management \\
PoF & Physics of Failure \\
RMSE & Root Mean Square Error \\
\hline
\end{tabular}




\begin{tabular}{|ll|}
\hline RUL & Remaining Useful Life \\
$\mathrm{R}^{2}$ & Coefficient of determination \\
SoH & State of Health \\
\hline
\end{tabular}

\begin{tabular}{|cl|}
\hline Notations & \\
$N$ & Number of inputs \\
$\alpha$ & Input prediction step \\
$\beta$ & Output prediction step \\
$h$ & Final prediction horizon \\
$t r n \_d a t a$ & Number of learning data samples \\
$S_{t}$ & Univariate time-series: $S_{t}=\left\{y_{1}, y_{2}, \ldots, y_{t}\right\}$ \\
$t$ & Time index \\
$\hat{y}_{t+1}$ & One-step ahead prediction \\
$\hat{y}_{t+h}$ & Final-step ahead prediction \\
\hline
\end{tabular}

\section{References}

[1] Bae S. J., Kim S.-J., Park J. I., Park C. W., Lee J.-H., Song I., Lee N., Kim K.-B., Park J.-Y. Lifetime prediction of a polymer electrolyte membrane fuel cell via an accelerated startup-shutdown cycle test. Int J Hydrogen Energy 2012; 37: 9775-9781.

[2] Yousfi Steiner N., Hissel D., Moçotéguy P., Candusso D., Marra D., Pianese C., Sorrentino M. Application of Fault Tree Analysis to Fuel Cell diagnosis. Fuel Cells 2012; 12, 302-309.

[3] Onanena R., Oukhellou L., Candusso D., Harel F., Hissel D., Aknin P. Fuel cells static and dynamic characterizations as tools for the estimation of their ageing time. Int J Hydrogen Energy 2011; 36: 17301739.

[4] Yousfi Steiner N., Hissel D., Moçotéguy P., Candusso D. Non intrusive diagnosis of polymer electrolyte fuel cells by wavelet packet transform. Int J Hydrogen Energy 2011; 36: 740-746.

[5] Wargo E. A., Dennison C. R., Kumbur E. C. Chapter 1 - Durability of Polymer Electrolyte Fuel Cells: Status and Targets. in Polymer Electrolyte Fuel Cell Degradation. ed Boston: Academic Press 2012, p. 114.

[6] Urbani F., Barbera O., Giacoppo G., Squadrito G., Passalacqua E. Effect of operative conditions on a PEFC stack performance. Int J Hydrogen Energy 2008; 33: 3137-3141.

[7] Wu J., Yuan X. Z., Martin J. J., Wang H., Zhang J., Shen J., Wu S., Merida W. A review of PEM fuel cell durability: Degradation mechanisms and mitigation strategies. J Power Sources 2008; 184: 104-119.

[8] Rodatz P., Büchi F., Onder C., Guzzella L. Operational aspects of a large PEFC stack under practical conditions. J Power Sources 2004; 128: 208-217.

[9] Chen C., Vachtsevanos G., Orchard M. E. Machine remaining useful life prediction: An integrated adaptive neuro-fuzzy and high-order particle filtering approach. Mechanical Systems and Signal Processing 2012; 28: 597-607.

[10] El-Koujok M., Gouriveau R., Zerhouni N. Reducing arbitrary choices in model building for prognostics: An approach by applying parsimony principle on an evolving neuro-fuzzy system. Microelectronics Reliability 2011; 51:310-320.

[11] Johnson P. Commercialization of prognostics systems leveraging commercial off-the-shelf instrumentation, analysis, and data base technologies. Presented at the Annual Conference of the Prognostics and Health Management Society 2011.

[12] Vachtsevanos G., Lewis F., Roemer M., Hess A., Wu B. Intelligent Fault Diagnosis and Prognosis for Engineering Systems: John Wiley \& Sons, Inc., 2007.

[13] Jardine A. K. S., Lin D., Banjevic D. A review on machinery diagnostics and prognostics implementing condition-based maintenance. Mechanical Systems and Signal Processing 2006; 20: 1483-1510.

[14] ISO13381-1. Condition monitoring and diagnostics of machines - prognostics - Part 1: General Guidelines. International Standard, ISO, 2004.

[15] Thurston M., Lebold M. Open Standards for Condition-Based Maintenance and Prognostic Systems, 2001.

[16] Batzel T. D., Swanson D. C. Prognostic Health Management of Aircraft Power Generators. IEEE Trans Aerospace and Electronic Systems 2009; 45: 473-482.

[17] Banerjee P. P., Avila R., He D., Shenliang W., Bechhoefer E. Discriminant Analysis Based Prognostics of Avionic Systems. IEEE Trans Systems, Man, and Cybernetics, Part C: Applications and Reviews 2007; 37: $1318-1326$ 
[18] Ofsthun S. Integrated vehicle health management for aerospace platforms. IEEE Instrumentation \& Measurement Magazine 2002; 5: 21-24.

[19] Lall P., Lowe R., Goebel K. Prognostics Health Management of Electronic Systems Under Mechanical Shock and Vibration Using Kalman Filter Models and Metrics. IEEE Trans Industrial Electronics 2012; 59: 4301-4314.

[20] Lall P., Hande M., Bhat C., Lee J. Prognostics Health Monitoring (PHM) for Prior Damage Assessment in Electronics Equipment Under Thermo-Mechanical Loads. IEEE Trans Components, Packaging and Manufacturing Technology 2011; 1: 1774-1789.

[21] Musallam M., Johnson C. M. Real-Time Compact Thermal Models for Health Management of Power Electronics. IEEE Trans Power Electronics 2010; 25: 1416-1425.

[22] Vichare N. M., Pecht M. G. Prognostics and health management of electronics. IEEE Trans Components and Packaging Technologies 2006; 29: 222-229.

[23] Strangas E. G., Aviyente S., Neely J. D., Zaidi S. S. H. The Effect of Failure Prognosis and Mitigation on the Reliability of Permanent-Magnet AC Motor Drives. IEEE Trans Industrial Electronics 2013; 60: 35193528.

[24] Ramuhalli P., Coble J., Meyer R. M., Bond L. J. Prognostics health management and life beyond 60 for nuclear power plants. In Future of Instrumentation International Workshop (FIIW) 2012, pp. 1-4.

[25] Riley D., Johnson J. Photovoltaic prognostics and heath management using learning algorithms. In 38th IEEE Photovoltaic Specialists Conference (PVSC) 2012, pp. 001535-001539.

[26] Baraldi P., Mangili F., Zio E. A Kalman Filter-Based Ensemble Approach With Application to Turbine Creep Prognostics. IEEE Trans Reliability 2012; 61: 966-977.

[27] Demo J., Andrews C., Friedersdorf F., Putic M. Diagnostics and prognostics for aircraft structures using a wireless corrosion monitoring network. In IEEE Aerospace Conference 2011, pp. 1-10.

[28] Chan Y. S., Song F., Lo C. C. J., Lee E., Lee S. W. R. Predictive modeling and experimental validation of lead-free solder joint reliability under temperature cycling. In Prognostics and Health Management Conference PHM '10 2010, pp. 1-8.

[29] Kobayshi M., Qiang Y. Reliability evaluation for specify factor of fatigue on power device. In Prognostics and Health Management Conference PHM '10 2010, pp. 1-6.

[30] Garg L., McClean S. I., Barton M., Meenan B. J., Fullerton K. Intelligent Patient Management and Resource Planning for Complex, Heterogeneous, and Stochastic Healthcare Systems. IEEE Trans Systems, Man and Cybernetics, Part A: Systems and Humans 2012; 42: 1332-1345.

[31] Frantzidis C. A., Bratsas C., Klados M. A., Konstantinidis E., Lithari C. D., Vivas A. B., Papadelis C. L., Kaldoudi E., Pappas C., Bamidis P. D. On the Classification of Emotional Biosignals Evoked While Viewing Affective Pictures: An Integrated Data-Mining-Based Approach for Healthcare Applications. IEEE Trans Information Technology in Biomedicine 2010; 14: 309-318.

[32] Zhang X., Pisu P. An Unscented Kalman Filter Based Approach for the Health-Monitoring and Prognostics of a Polymer Electrolyte Membrane Fuel Cell. Presented at the Annual Conference of the Prognostics and Health Management Society 2012, Minneapolis.

[33] Marra D., Sorrentino M., Pianese C., Iwanschitz B. A neural network estimator of Solid Oxide Fuel Cell performance for on-field diagnostics and prognostics applications. J Power Sources 2013; 241: 320-329.

[34] Jouin M., Gouriveau R., Hissel D., Péra M.C., Zerhouni N. PHM of Proton-Exchange Membrane Fuel Cells - A Review. Chemical Engineering Transactions 2013; 33: 1009-1014.

[35] Kumar A., Srivastava A., Goel N., Nayak A. Model based approach and algorithm for fault diagnosis and prognosis of coated gas turbine blades. In IEEE/ASME International Conference on Advanced Intelligent Mechatronics (AIM) 2010, pp. 800-805.

[36] Byington C. S., Watson M., Edwards D., Stoelting P. A model-based approach to prognostics and health management for flight control actuators. In IEEE Aerospace Conference Proceedings 2004; 6: 3551-3562.

[37] Chookah M., Nuhi M., Modarres M. A probabilistic physics-of-failure model for prognostic health management of structures subject to pitting and corrosion-fatigue. Reliability Engineering \& System Safety 2011; 96: 1601-1610.

[38] Jiajie F., Yung K. C., Pecht M. Physics-of-Failure-Based Prognostics and Health Management for HighPower White Light-Emitting Diode Lighting IEEE Trans Device and Materials Reliability 2011; 11: 407416.

[39] Tobon-Mejia D. A., Medjaher K., Zerhouni N., Tripot G. A. Data-Driven Failure Prognostics Method Based on Mixture of Gaussians Hidden Markov Models. IEEE Trans Reliability 2012; 61: 491-503.

[40] Xiong R., Sun F., Gong X., Gao C. A data-driven based adaptive state of charge estimator of lithium-ion polymer battery used in electric vehicles. Applied Energy 2014; 113: 1421-1433.

[41] Si X.-S., Wang W., Hu C.-H., Zhou D.-H. Remaining useful life estimation - A review on the statistical data driven approaches. European Journal of Operational Research 2011; 213: 1-14. 
[42] Zio E., Di Maio F. A data-driven fuzzy approach for predicting the remaining useful life in dynamic failure scenarios of a nuclear system. Reliability Engineering \& System Safety 2010; 95: 49-57.

[43] Ramasso E., Gouriveau, R. RUL estimation by classification of predictions: an approach based on a neurofuzzy system and Demspter-Shafer theory of belief functions. IEEE Trans Reliability, to appear 2013.

[44] Heng A., Zhang S., Tan A. C. C., Mathew J. Rotating machinery prognostics: State of the art, challenges and opportunities. Mechanical Systems and Signal Processing 2009; 23: 724-739.

[45] Pecht M., Jaai R. A prognostics and health management roadmap for information and electronics-rich systems. Microelectronics Reliability 2010; 50: 317-323.

[46] Dai J., Das D., Pecht M. Prognostics-based risk mitigation for telecom equipment under free air cooling conditions. Applied Energy 2012; 99: 423-429.

[47] Dragomir O. E., Dragomir F., Gouriveau R., Minca E. Medium term load forecasting using ANFIS predictor. In 18th Mediterranean Conference on Control \& Automation (MED) 2010, 2010, pp. 551-556.

[48] Gouriveau R., Ramasso E. From real data to remaining useful life estimation: an approach combining neuro-fuzzy predictions and evidential Markovian classifications. In 38th ESReDA Seminar Advanced Maintenance Modelling., Pecs 2010, Hongrie.

[49] El-Koujok M., Gouriveau R., Zerhouni N. Towards a Neuro-Fuzzy System for time series forecasting in Maintenance Applications. In 17th Triennal World Congress of the International Federation of Automatic Control, IFAC'08 2008, Seoul, Corée.

[50] Forouzanfar M., Dajani H. R., Groza V. Z., Bolic M., Rajan S. Feature-Based Neural Network Approach for Oscillometric Blood Pressure Estimation. IEEE Trans Instrumentation and Measurement 2011; 60; 2786-2796.

[51] Assaleh K. Extraction of Fetal Electrocardiogram Using Adaptive Neuro-Fuzzy Inference Systems. IEEE Trans Biomedical Engineering 2007; 54: 59-68.

[52] Behloul F., Lelieveldt B. P. F., Boudraa A., Janier M. F., Revel D., Reiber J. H. C. Neuro-fuzzy systems for computer-aided myocardial viability assessment. IEEE Trans Medical Imaging,2001; 20: 1302-1313.

[53] Changliang X., Chen G., Tingna S. A Neural-Network-Identifier and Fuzzy-Controller-Based Algorithm for Dynamic Decoupling Control of Permanent-Magnet Spherical Motor. IEEE Trans Ind Electron 2010; 57: 2868-2878.

[54] Awadallah M. A., Morcos M. M. Automatic diagnosis and location of open-switch fault in brushless DC motor drives using wavelets and neuro-fuzzy systems. IEEE Trans Energy Conv 2006; 21: 104-111.

[55] Grabowski P. Z., Kazmierkowski M. P., Bose B. K., Blaabjerg F. A simple direct-torque neuro-fuzzy control of PWM-inverter-fed induction motor drive. IEEE Trans Ind Electron 2000; 47: 863-870.

[56] Fennie D. R. C., Barbetta J., Singh P. Fuzzy Logic-Based State of Health Determination of PEM Fuel Cells. In Procs. EVS-18, Berlin, Germany, 2001.

[57] Vural Y., Ingham D. B., Pourkashanian M. Performance prediction of a proton exchange membrane fuel cell using the ANFIS model. Int J Hydrogen Energy 2009; 34: 9181-9187.

[58] Jang J. S. R., Sun C. T. Predicting chaotic time series with fuzzy if-then rules. In Second IEEE International Conference on Fuzzy Systems 1993; 2: 1079-1084.

[59] Herrera L. J., Pomares H., Rojas I., Guillén A., Prieto A., Valenzuela O. Recursive prediction for long term time series forecasting using advanced models. Neurocomputing 2007; 70: 2870-2880.

[60] Jun Z., Chung H. S. H., Wai-Lun L. Chaotic Time Series Prediction Using a Neuro-Fuzzy System with Time-Delay Coordinates. IEEE Trans Knowledge and Data Engineering 2008; 20: 956-964.

[61] Wu X.-J., Zhu X.-J., Cao G.-Y., Tu H.-Y. Nonlinear modeling of a SOFC stack based on ANFIS identification. Simulation Modelling Practice and Theory 2008; 16: 399-409.

[62] Gao X. Z., Ovaska S. J. Soft computing methods in motor fault diagnosis. Applied Soft Computing 2001; 1: $73-81$.

[63] Nauck D., Kruse R. Obtaining interpretable fuzzy classification rules from medical data. Artificial Intelligence in Medicine 1999; 16: 149-169.

[64] Solano Martínez J., John R. I., Hissel D., Péra M.-C. A survey-based type-2 fuzzy logic system for energy management in hybrid electrical vehicles. Information Sciences 2012; 190: 192-207.

[65] Jang J. S. R. ANFIS: adaptive-network-based fuzzy inference system. IEEE Trans Systems, Man and Cybernetics 1993; 23: 665-685.

[66] Ghazali R., Hussain A. J., Liatsis P., Tawfik H. The application of ridge polynomial neural network to multi-step ahead financial time series prediction. Neural Computing and Applications 2008; 17: 311-323.

[67] Van Gestel T., Suykens J. A. K., Baestaens D. E., Lambrechts A., Lanckriet G., Vandaele B., De Moor B., Vandewalle J. Financial time series prediction using least squares support vector machines within the evidence framework. IEEE Trans Neural Networks 2001; 12: 809-821.

[68] Kusiak A., Haiyang Z., Zhe S. Short-Term Prediction of Wind Farm Power: A Data Mining Approach. IEEE Trans Energy Conversion 2009; 24: 125-136. 
[69] Taylor J. W., McSharry P. E., Buizza R. Wind Power Density Forecasting Using Ensemble Predictions and Time Series Models. IEEE Trans Energy Conv 2009; 24: 775-782.

[70] Potter C. W., Negnevitsky M. Very short-term wind forecasting for Tasmanian power generation. IEEE Trans Power Systems 2006; 21: 965-972.

[71] Tamura H., Tanno K., Hisasi T., Vairappan C., Zheng T. Recurrent type ANFIS using local search technique for time series prediction. In IEEE Asia Pacific Conference on Circuits and Systems APCCAS 2008, pp. 380-383.

[72] Daijin K., Chulhyun K. Forecasting time series with genetic fuzzy predictor ensemble. IEEE Trans Fuzzy Systems 1997; 5: 523-535.

[73] MC Mackey L. G. Oscillation and chaos in physiological control systems. Science 1977; 197: 287-289.

[74] Gouriveau R., Zerhouni N. Connexionist-Systems-Based Long Term Prediction Approaches for Prognostics. IEEE Trans Reliability 2012; 61: 909-920.

[75] Razani M., Yazdani-Chamzini A., Yakhchali S. H. A novel fuzzy inference system for predicting roof fall rate in underground coal mines. Safety Science 2013; 55: 26-33.

[76] Duzen H., Aydin H. Sunshine-based estimation of global solar radiation on horizontal surface at Lake Van region (Turkey). Energy Conversion and Management 2012; 58: 35-46.

[77] Laffly E. Modélisation d'une Pile à Combustible de Type PEMFC Intégrant les Phénomènes de Vieillissement. Ph.D thesis, University of Franche-Comte, France, 2008 [in French]. 